Article

\title{
Social Vulnerability across the Great Lakes Basin: A County-Level Comparative and Spatial Analysis
}

\author{
Joshua T. Fergen * ${ }^{(}$and Ryan D. Bergstrom \\ Program in Geography, University of Minnesota Duluth, Duluth, MN 55812, USA; rbergstr@d.umn.edu \\ * Correspondence: ferge176@d.umn.edu
}

Citation: Fergen, J.T.; Bergstrom, R.D. Social Vulnerability across the Great Lakes Basin: A County-Level Comparative and Spatial Analysis. Sustainability 2021, 13, 7274.

https://doi.org/10.3390/su13137274

Academic Editor: Md Younus

Received: 18 May 2021

Accepted: 26 June 2021

Published: 29 June 2021

Publisher's Note: MDPI stays neutral with regard to jurisdictional claims in published maps and institutional affiliations.

Copyright: (C) 2021 by the authors. Licensee MDPI, Basel, Switzerland. This article is an open access article distributed under the terms and conditions of the Creative Commons Attribution (CC BY) license (https:/ / creativecommons.org/licenses/by/ $4.0 /)$.

\begin{abstract}
Social vulnerability refers to how social positions affect the ability to access resources during a disaster or disturbance, but there is limited empirical examination of its spatial patterns in the Great Lakes Basin (GLB) region of North America. In this study, we map four themes of social vulnerability for the GLB by using the Center for Disease Control's Social Vulnerability Index (CDC SVI) for every county in the basin and compare mean scores for each sub-basin to assess inter-basin differences. Additionally, we map LISA results to identify clusters of high and low social vulnerability along with the outliers across the region. Results show the spatial patterns depend on the social vulnerability theme selected, with some overlapping clusters of high vulnerability existing in Northern and Central Michigan, and clusters of low vulnerability in Eastern Wisconsin along with outliers across the basins. Differences in these patterns also indicate the existence of an urban-rural dimension to the variance in social vulnerabilities measured in this study. Understanding regional patterns of social vulnerability help identify the most vulnerable people, and this paper presents a framework for policymakers and researchers to address the unique social vulnerabilities across heterogeneous regions.
\end{abstract}

Keywords: social vulnerability; Great Lakes Basin; cluster outlier analysis; LISA; spatial inequality

\section{Introduction}

The Great Lakes Basin (GLB), along the U.S.-Canadian border, is home to nearly 30 million people [1], is a global economic engine, producing more than $\$ 5$ trillion in economic output annually [2], and is increasingly under threat from climate-driven disturbances such as rapidly changing water levels, the intensification of storm events, and harmful cyanobacterial blooms [3]. At the same time, the heterogeneity of the social landscape of the basin is underpinned by the unequal distribution of social vulnerability. Therefore, it is critical to identify which areas are most socially vulnerable to identify place-based solutions that facilitate increased resiliency.

Using the Center for Disease Control and Prevention's Social Vulnerability Index [4], this study examines the spatial distribution of social vulnerability across the GLB and identifies hotspots based on different characteristics of social vulnerability. Specifically, this study hopes to determine, (1) how social vulnerability is distributed across the basin, (2) where spatial clustering of vulnerabilities exists, and (3) if social vulnerability differs across the region. While spatial assessments of social science data are abundant for other coastal communities in the United States, they are lacking within the GLB [5,6]. As such, this study fills an important gap in our understanding of social vulnerability in the Great Lakes by providing stakeholders and decision-makers a descriptive account of the social landscape that has the potential to aid in community resiliency and adaptive capacity [7-9].

\subsection{Social Vulnerability}

The social science literature on concepts such as resilience, capacity, and vulnerability has grown with emergent climate change challenges, developing more nuanced ideas 
that better link social and natural systems together [10-12]. Social vulnerability refers to how socioeconomic status intersects with race, place, and local institutional capacities that shape the ability of communities and social groups within them to respond to disasters and extreme events that disrupt day-to-day activities [7,11]. Social vulnerability results when social, political, and economic processes combine to produce heightened susceptibility to hazards for some populations [13-16]. The application of the concept can be found in health research, hazard mitigation planning, and environmental social sciences, but the use and selection of indicators can significantly vary $[9,12,15,17,18]$.

Social vulnerability is also shaped by a social group or individual's ability to access and utilize resources to cope with an event or risk $[19,20]$. Resources consist of both material, psychosocial, and institutional support, but these can vary significantly place-toplace and by the type of event. For example, flooding from extreme precipitation events impacts rural communities by damaging infrastructure that is expensive for municipalities and townships with small tax bases to rebuild, and the distance to hospital services can make it difficult to treat people who need medical attention. Furthermore, many rural places in the GLB contain natural resource-dependent communities, places dependent on the natural environment to maintain a livelihood, which makes them more vulnerable to environmental perturbations along with global market fluctuations associated with extractive industries and raw commodity production [21,22]. This may be different than in urban areas, where there may be more concern with water contamination from CSOs and impervious surface runoff, and damage to private property $[3,23,24]$.

Social vulnerability also has a geographic pattern in the United States and identifying the unique context of these vulnerabilities is needed for city and regional planners to enhance the resiliency of places $[7,10,25,26]$. Identifying areas that are more socially vulnerable than others is difficult, as the context of local places can shape the degree to which any indicator impacts vulnerability $[16,27]$. Rather than long-term approaches to reduce social vulnerability, most community efforts focus on short-term strategies on improving access to emergency response services which are less effective in addressing the root causes of social vulnerability $[20,28]$. This has led to a growing recognition that economic indicators of community capacity and resilience may be masking inequalities within places [20]. This idea suggests that what determines the usefulness of social vulnerability indicators is the local context that shapes how these indicators affect the lived experience, behaviors, and responses of social groups when disaster strikes. However, mapping out indicators at the county level over time and space provides a way to establish methods and metrics for tracking and evaluating change, allowing for subnational comparisons and the identification of geographically linked social vulnerabilities.

\subsection{Measuring Social Vulnerability}

The complexity of a concept like social vulnerability is highlighted by the multiple dimensions and functions that underpin it, including adaptive capacity, exposure to harm, and sensitivity to events $[9,20,29]$. Adaptive capacity refers to the process of adjusting to a changing environment to reduce the risk of harm or exploit new opportunities [29]. Exposure refers to how the presence of people in places that could be adversely affected by a hazard or disturbance (i.e., proximity to flood plain), while sensitivity reflects the degree to which social systems are susceptible to disruption [29]. Social vulnerability comes in multiple forms and is frequently measured by assessing aggregated data for an area on socioeconomic status, household composition, minority make-up and language use, and housing type and transportation $[4,9,17,29]$. Selected indicators of a social vulnerability assessment are also influenced by non-local economic factors, political trends, and institutional processes, thus their construct validity may change over time [29,30]. Despite the differences in the indicators used, the common objective of social vulnerability research is to identify and enhance the adaptive capacity of places to deal with a range of social and ecological events, from macro changes (economic transitions, climate change) to situational events (extreme flood event, closing of local employer) $[9,15,18,29,30]$. 
An empirical understanding of the spatial distribution and determinants of social vulnerability associated with climate change is expanding but still nascent, requiring many spatial scales to be analyzed, monitored, and characterized throughout different spatial frameworks and techniques [7-9,26,31]. However, there is significant debate on the validity of quantitative approaches to examine and compare social vulnerability because local context shapes how any particular predictor influences that location's vulnerability. That is, a comparable index that captures the nuances of vulnerability from place to place will either miss critical variables and their interactions for the sake of a parsimonious model or become too cumbersome to be useful at the larger, national-level $[8,9,17,25]$.

\subsection{Great Lakes Context}

For the past three decades, the Great Lakes region has witnessed uneven population growth, its population has aged, and it has also become more racially and ethnically diverse [1]. These changing demographic characteristics have implications for the region's economy, its governance [32], and particularly for its vulnerability and resiliency to climate-driven disturbances $[33,34]$ which are increasing in their intensity, frequency, and magnitude [35,36].

Since 1960, the total population of the United States has grown over 33 percent, while the population of the Great Lakes region has only grown 13 percent during that same period [1]. Even within the region itself, demographic changes are heterogeneous and differ between sub-basins, states, and countries. At the national level, the vast majority of growth in the region has taken place in Canada, which has experienced 30 percent growth, while the United States only grew 16 percent. At the sub-basin level, over 70 percent reside within the Lake Michigan or Lake Erie watersheds, while only two percent live within the Lake Superior watershed (Lake Huron and Lake Ontario constitute nine and 17 percent respectively) [37]. At the state level, Minnesota, Wisconsin, and Indiana are considered moderate-growth states, with 2000 to 2010 growth rates of $0.79,0.61$, and 0.67 percent respectively; while Illinois, Ohio, and Michigan are considered slow or no growth states [32]. Finally, it has been urban centers that have seen the largest changes in the basin, with cities such as Chicago, Detroit, and Cleveland all losing population, while Toronto, Montreal, and Ottawa have witnessed population growth [1]. The region is also aging, and that aging has come at the cost of younger age cohorts. In particular, the basin experienced declines in the 25-to-34 and 35-to-44-year-old cohorts, as well as children younger than 15. Looking into the future, these trends continue with the potential to have large implications for labor forces throughout the region [32].

Lastly, although demographically the GLB has become more diverse in recent decades, the region remains more homogenous than the United States as a whole, with Black, Hispanic, Asian, and other non-Caucasian races only accounting for a quarter of the region's population (up from 16 percent in 1990). Diversification is largely being driven by immigration, which today accounts for 34 percent of the population (up from 26 percent in 1960). That said, immigrants to the Great Lakes region differ from those arriving in the rest of the country, particularly as it pertains to their source region. At the national level, immigrants predominantly arrive from Central and South American, the Caribbean, and East and Southeastern Asia, while in the Great Lakes migrants arrive from Europe, Central, and Southern Asia, the Middle East, and Africa [1,32]. By 2040, the makeup of the region is projected to change even further, as diversification is accelerated, driven by increases in Hispanic populations, with the most pronounced increases occurring in Illinois [32].

Lake Superior is the deepest, coldest, and biggest of the Great Lakes, but is also experiencing some of the more extreme environmental changes due to its more northern location [36,38]. It is warming the fastest, which is contributing to the loss of ice cover and could exacerbate behavioral changes and the distribution of species throughout the lake, including the migration of non-native invasive species and transformations of existing ecosystems [38,39]. The recent high water levels combined with major storms have led to an increase in property damage and community development initiatives, with notable 
examples from the city of Duluth, Minnesota [40]. Chemical contamination from both current industrial practices and legacy effects of mining industries produce one threat while increasing PFOS and personal care products are being introduced via groundwater transfer, contaminating wildlife and food systems [41]. Other major ecosystem and environmental stressors include shoreline development, invasive species, habitat and wetland degradation and loss, inland forest fragmentation, and the rising concern on the emergence of algal blooms in parts of the lake [42].

Lake Michigan is the second largest lake and is the only Great Lake completely within the U.S. It contains the world's largest collection of freshwater sand dunes and is home to a key migratory bird route in North America, but also has the dubious distinction as the deadliest lake due to strong rip currents that lead to more accidental drownings than other Great Lakes [42,43]. It contains several large metropolitan areas that became pivotal manufacturing hubs and is the most populous basin. One of the biggest issues on Lake Michigan is the rate of erosion and sedimentation that occurs. Being the most developed shoreline, erosion causes significant financial costs as homes and properties are reclaimed by the lake [44,45]. Common stressors for Lake Michigan are water pathogens, erosion and sedimentation, and contamination from a variety of industrial, agricultural, and household practices [42].

Lake Huron has the largest drainage basin and the longest shoreline in the Great Lakes system, but remains the second-largest by surface area, third-largest by volume, and contains over 30,000 islands, including the largest freshwater island in the world [46,47]. The Lake Huron Basin contains a mixture of tourism and agriculture while boasting a productive fishery in Saginaw Bay. Few cities exist in the Huron Basin, as the basin is characterized as mostly rural, particularly in the northern areas in Ontario. Recent challenges in Lake Huron management include chemical contamination, invasive species, nutrient imbalances, and the degradation of natural habitats [47].

Lake Erie is the smallest Great Lake by volume but contains nearly 12 million people (33\% of the GLB population) [36,48]. Being the shallowest lake, it rapidly changes temperature in summer and can freeze over in the winter. The land surrounding the lake is mostly developed as urban areas or agriculture, and governance around the lake is noted for the complexity of social groups and actors using its resources. Of particular concern are the harmful algal blooms, which are toxic and pose significant threats to public safety, particularly with 12 million dependent on the lake for drinking water [48]. As such, there is a particular need to understand the drivers of eutrophication and the development of HABs, but also a need to study the distribution of critical habitats, distribution of contaminants, and how storm events impact beach water quality in a basin with significant coverage of impervious surfaces [48].

Lake Ontario is the smallest lake in terms of surface area but is very deep with strong currents as it operates as the gateway to the ocean through the St. Lawrence River. Located at the lowest elevation, all of the other Great Lakes drain into it, suggesting that threats tend to be amplified here. The landscape around the lake is largely rural along the U.S. side but contains the city of Toronto, Canada, a globally integrated industrial city. Similar to other lakes, the main environmental issues facing Lake Ontario include the management of invasive species, loss of biodiversity, degradation of the lower food chain, and chemical contaminants remain a concern [49]. Relatedly, a rising concern has been on property damage, with Governor Cuomo of New York filed a lawsuit against the International Joint Commission responsible for managing risks associated with the Great Lakes for negligence, nuisance, and trespassing for not adequately protecting properties via water outflow management [50].

Given the combination of economic, demographic, and climatic shifts in the region, governments and civic organizations at multiple scales are recognizing the need to promote climate adaptation with the need to identify and protect the most socially vulnerable populations $[4,14,36]$. Furthermore, it is increasingly recognized that social vulnerability has a geographic pattern $[7,9]$, yet no study has specifically focused on the largest freshwater 
system in the world, one that is currently experiencing drastic shifts in climate [35]. This study fills this gap by analyzing these spatial patterns, providing a deeper understanding of the most socially and geographically vulnerable populations.

\section{Materials and Methods}

To understand the spatial patterns of social vulnerability in the GLB (Figure 1), this study relies on several techniques. First, social vulnerabilities are mapped at the county level across the GLB. The data used in this study relies on the Center for Disease Control's Social Vulnerability Index [4], a TIGER/Line shapefile of all U.S. counties [51], and the United States Geological Survey (USGS) Water Basin Boundaries of the Great Lakes [52]. All data is publicly available online [4,51,52].

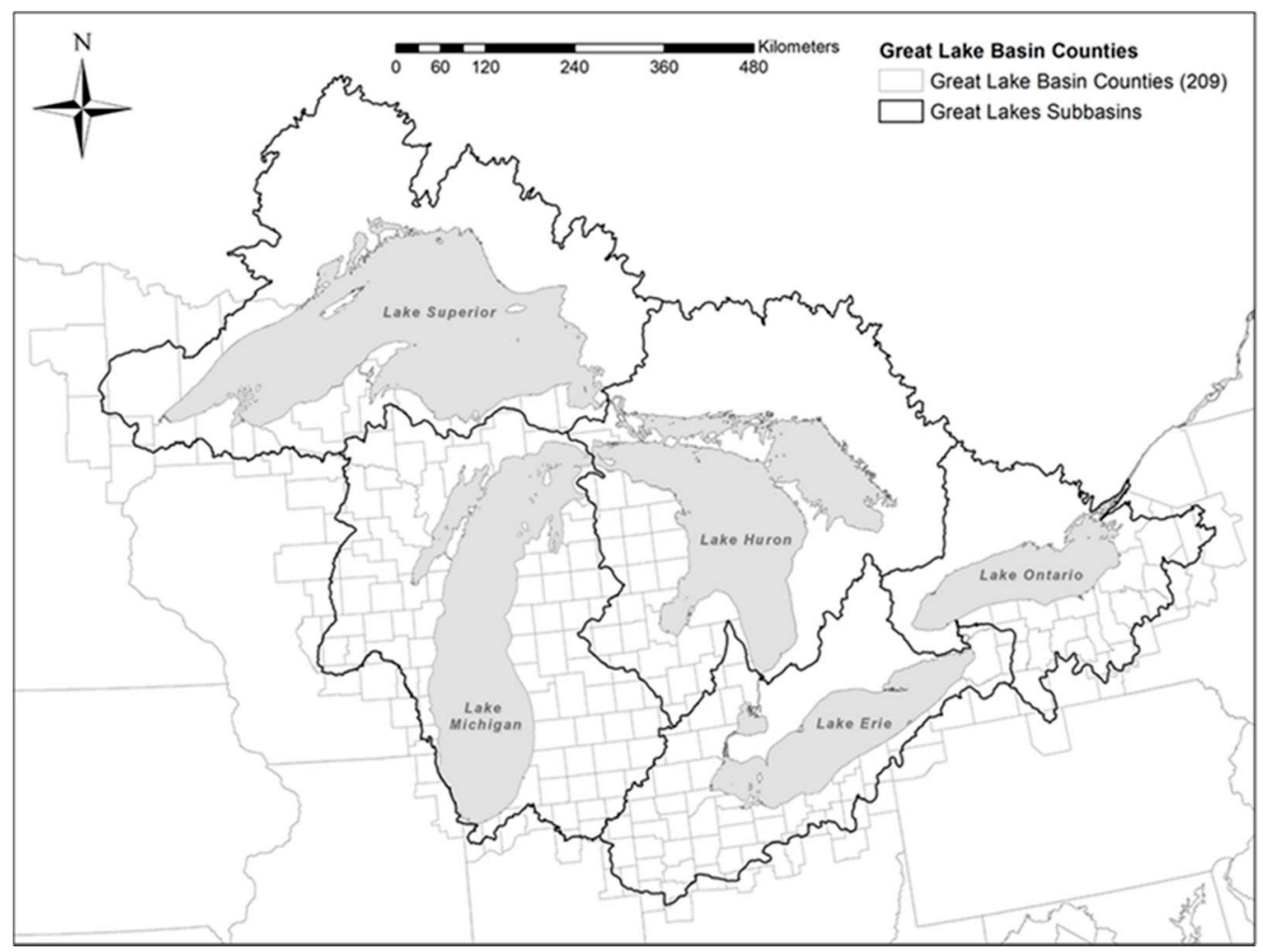

Figure 1. Study Area.

SVI Data was spatially merged in ArcMap 10.8.1 with county-level spatial extents, and two variables were created to identify which counties lie in the Great Lake Basin, and their specific lake basin. Each county that intersected the basin was identified as a Great Lake Basin county, but several counties stretch across multiple basins, particularly in Michigan. To designate a specific lake basin, the drainage basin that covered the majority of the surface area of the county was selected to represent these basins. This resulted in 209 Great Lake Basin counties for the database, where the file was then converted into a .csv file and uploaded to IBM's Statistical Package for the Social Sciences (SPSS) ver. 27 for statistical analysis.

\subsection{Social Vulnerability}

The Center for Disease Control's SVI uses 15 variables provided by the American Community Survey (ACS) 5-year estimate (Table 1) to assess four sub-themes of social vulnerability. The ACS is used instead of census numbers because they annually survey neighborhoods, providing important updates to demographic changes that occur between the 10-year periods between census counts. Each of these variables is available at the county level through the CDC and ACS. To create the indices, the estimated percentage of 
the ACS variable at the county level is added as a way to capture relative measures across different geographies (see [4] for more details).

Table 1. List of Social Vulnerability Themes and ACS Variables.

\begin{tabular}{cc}
\hline Social Vulnerability Theme & ACS Variables (2014-2018) \\
\hline Socioeconomic Status & $\%$ Below Poverty \\
& $\%$ Unemployed \\
Income per Capita & \% w No High School Diploma \\
\hline Household Composition and Disability & $\%$ Age 65 or Older \\
& $\%$ Age 17 or Younger \\
Minority Status and Language & $\%$ Civilians w $/$ Disability \\
\hline & $\%$ Minority \\
& $\%$ Speaks English "Less than Well” \\
\hline Housing Type and Transportation & $\%$ Mobile Homes \\
& $\%$ Crowding \\
& $\%$ Living in Group Quarters \\
\hline
\end{tabular}

\subsubsection{Socioeconomic Status}

Socioeconomic status refers to the social position a person or group has in society based on several material and non-material factors that affect access to resources [31]. This concept acknowledges that several factors combine to shape socioeconomic status, and the U.S. census tracts established indicators for it: employment, income, and education. Research has shown that those with lower incomes are disproportionately impacted by disasters because they have fewer means to financially adapt to the loss of housing or disruptions to daily livelihoods, often resulting in cycles of joblessness and poverty [9]. Furthermore, those with less education are less likely to act on new hazard risk information, less likely to have the economic means to mitigate impacts from a disaster event, with an added association with more burdensome experiences navigating the bureaucratic loopholes needed to receive assistance [7,9]. The CDC measures this concept by adding county percentages of persons below the poverty line, unemployed persons 16 and above, per capita income, and persons 25 and over without a high school diploma [9].

\subsubsection{Household Composition and Disability}

Household composition and disability refers to how members of a particular household are in socially vulnerable groups, frequently defined as young children, the elderly, and those with disabilities $[9,13]$. The increase in vulnerability from having a child is the result of the child-bearing responsibility and the lack of adequate emergency response services specifically for children [53]. The elderly population is more likely to require special assistance in response to a disaster and may not be able to adequately care for themselves in times of disruption, placing additional responsibility on emergency services and family members [54]. Additionally, the rise of single-parent households has brought additional challenges to individuals managing a more vulnerable population, including less income and less division of responsibilities [7,55]. The CDC SVI measures this concept with the percentage of people aged 65 and older in a household, the percentage of people age 17 and younger, the percentage of people with a disability, and the percent of single-parent households with children living with them.

\subsubsection{Minority Status and Language}

Minority status and language refers to how institutional practices have created and maintained inequalities based on race and immigration status in the U.S., which has a direct bearing on a social group's ability to respond, cope, and adapt to disaster $[9,13]$. Income 
inequality between races in the U.S. is significant, and this translates into the differential ability for some groups to be able to afford to adapt to disaster [54]. Additionally, the rise of immigration in the U.S. from Central and South America has created new geographies of Spanish-speaking communities in areas that have not traditionally seen these populations, and this can limit the ability for disaster communication to reach all subgroups if there are not proper translation services and can impact social networks that provide access to additional services [56,57]. The CDC SVI measures this concept with the percentage of minority residents and the percent of persons who speak English less than well.

\subsubsection{Housing Type and Transportation}

Housing type and transportation refers to how housing structures are capable of withstanding a disaster and provide adequate safety, while personal transportation options relate to the ability to physically relocate $[7,9,56]$. This theme is directly related to socioeconomic status, as those with fewer means are more likely to occupy crowded housing and housing with no basements $[13,58]$. Residents in urban areas may also have more options for public transportation services, all of which can be immediately shut down during a disaster, leaving residents without access to a working vehicle immobile [9]. Additionally, people living in group quarters such as dormitories, assisted living centers, and prisons represent another vulnerability, as these living quarters have limited exits and populations may require special attention during evacuations $[13,29]$. The CDC SVI measures this concept with the percentage of housing structures with 10 or more units, percentage of mobile homes, percentage of houses with more people than rooms, percent of households with no vehicle access, and percent of persons living in group quarters.

\subsection{Spatial and Statistical Analysis}

To examine the spatial pattern of social vulnerability across the GLB, this study uses a cluster and outlier analysis, using a bivariate local indicator of spatial association (LISA) technique $[59,60]$. Spatial autocorrelation is the degree to which a value at one unit of measurement is similar to the surrounding units, where the value represents the measure of the dispersion of a spatial pattern, known as Moran's I. Moran's I is a measure statistic (one value across all units) ranging from -1 to 1 , where values closer to -1 represent even spatial dispersion and values closer to 1 represent spatial clustering, and values near 0 represent a more random distribution of the variable $[59,60]$. A bivariate LISA analysis maps the local Moran's I values based on a scatterplot of the value of each observation and the summed values of each neighbor [60,61].

Similarly, a local Moran's I can be calculated for each unit assessed to identify patterns of clustering and dispersion $[59,60]$. These relative values are produced as z-scores with associated $p$-values to assess the null hypothesis that a selected variable is randomly, spatially distributed $[26,61]$. LISA values that are unexpectedly higher or lower than the global Moran's I can be mapped and represent five forms of spatial patterns: high value units next to other high value units (high-high), high-value units next to low-value units (high-low), low-value units next to high value units (low-high), low-value units next to other low-value units (low-low), and non-significant differences [61]. Previous research has applied univariate LISA statistics to identify clusters and outliers and other spatial patterns of social vulnerability $[6,16,25,26,62-65]$.

ArcMap 10.8 was used to perform the cluster and outlier analysis and produce the maps for each SVI theme (see [66] for formula details). This analysis is found by accessing the ArcToolbox and navigating to "Spatial Statistics Tools" > "Mapping Clusters" > "Cluster and Outlier Analysis (Anselin Local Morans I)." Inverse distance is used and the false discovery correction is applied for analysis. The data table produced from merging the CDC SVI with county and Great Lake Basin location was exported and re-uploaded into SPSS 27. A data quality check was performed and descriptive statistics were generated. To assess differences between the GLB and the U.S. and the differences across basins within the GLB, a $t$-test, and ANOVA test were performed and detailed below. 


\section{Results}

The following results highlight the SVI scores and LISA analysis, and illustrate the spatial distribution of social vulnerability within the GLB, whether spatial clustering exists, and whether there are significant variations of vulnerability across the basin.

\subsection{Socioeconomic Vulnerability}

Overall, the region appears fairly heterogeneous in terms of socioeconomic vulnerability, but several small patterns are observable from the SVI scores (Figures 2 and 3). First, Lake Superior is most vulnerable to socioeconomic status along stretches of the southern shores of Wisconsin and upper Michigan, which are very rural parts of the basin. Second, the Lake Michigan Basin is fairly diverse, with less socioeconomic vulnerability in the western part of the basin in the state of Wisconsin, but more vulnerability in the northern basin (upper Michigan) and eastern basin (central Michigan). The Lake Huron Basin appears the most vulnerable as the western and southern basin are some of the most vulnerable parts of the state of Michigan. The Lake Erie Basin has relatively lower SVI scores for socioeconomic vulnerability, with two higher-value scores for the counties with Detroit, $\mathrm{MI}$ and Ashtabula, $\mathrm{OH}$. The Lake Ontario Basin is fairly consistent in terms of SVI score on socioeconomic vulnerability, with one county on the outer northeastern edge of the basin, and a small group of lower scores across the eastern part of the Lake Ontario basin.

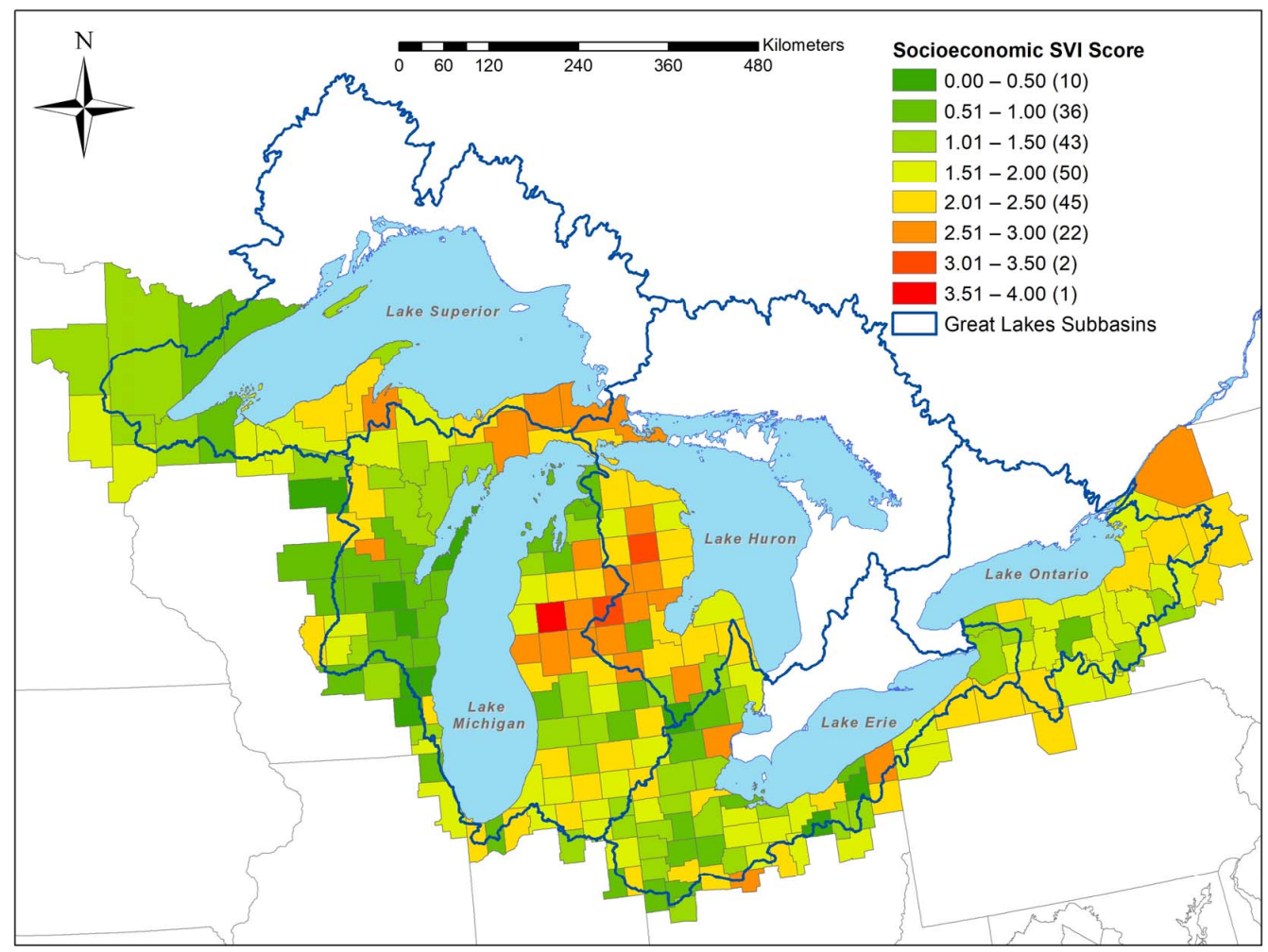

Figure 2. SVI Score for Socioeconomic Vulnerability.

Several results stand out from the LISA. First, there are three noticeable areas of highhigh clusters (26 total counties), or areas where several unit scores are significantly higher than by random chance alone in a neighborhood. One of the areas includes a significant portion of the northern half of Michigan across the Lake Huron and Lake Michigan Basins, a rural area significantly less populated than the lower half of the state. An isolated county (Luce County) in the upper peninsula of Michigan in the Lake Superior Basin is also identified, as well as another county in Pennsylvania (Erie County) in the Lake Erie Basin. Interestingly, Luce County is the second-least populated county in Michigan with under 
7000 residents, whereas Erie County contains the Erie metropolitan area and is home to over 250,000 people.

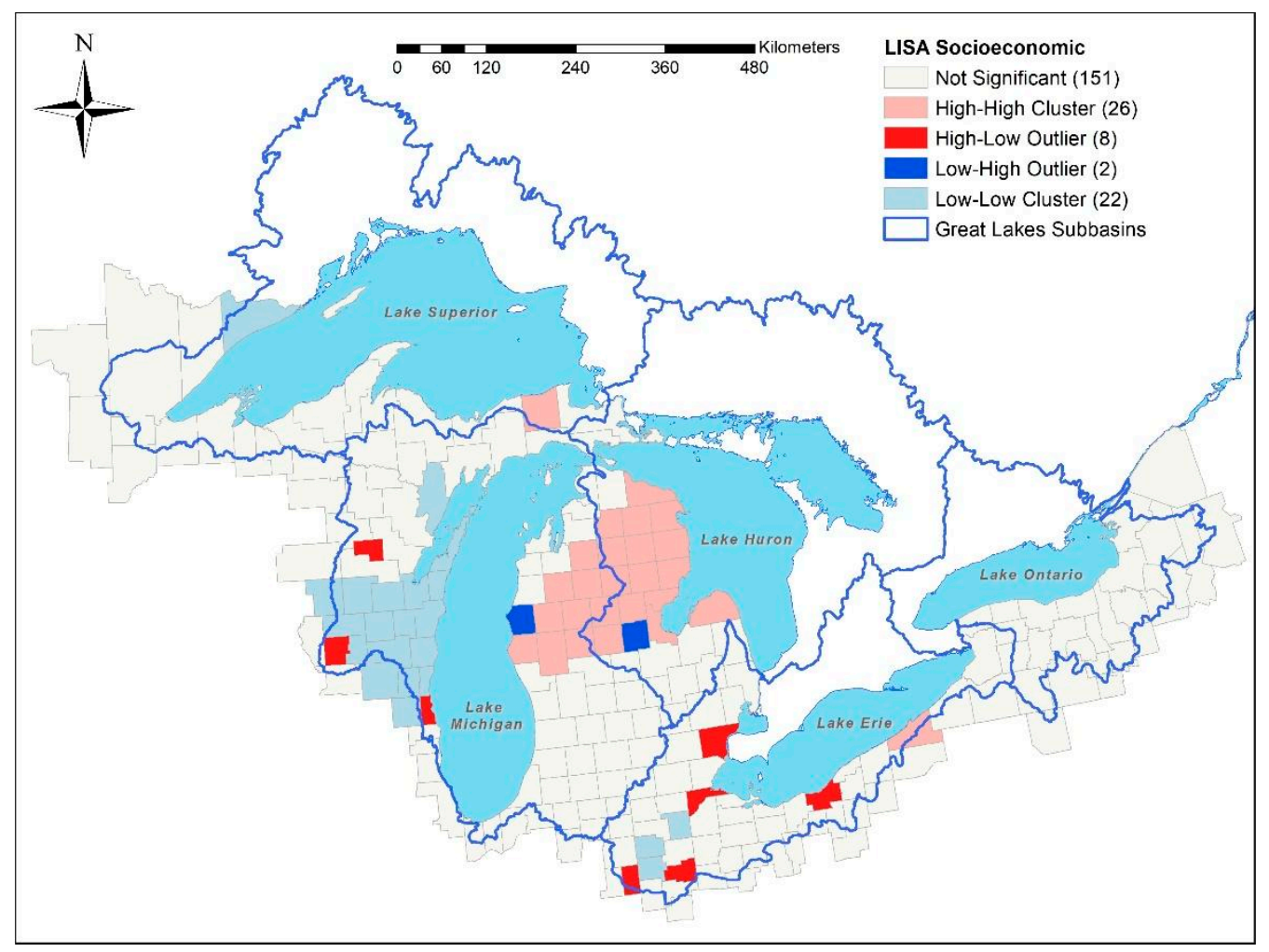

Figure 3. LISA Results for Socioeconomic Vulnerability.

Second, there are a few notable areas characterized by low-low clusters (22 total counties), or counties with low SVI scores in a neighborhood with other counties with low SVI scores, particularly along the western shoreline of Lake Michigan in Wisconsin and Michigan, with an isolated county in Minnesota's North Shore of Lake Superior, and three other counties in Ohio's Lake Erie. The largest cluster (18 of 22 counties) is the Lake Michigan-Wisconsin cluster, which is a region dominated by manufacturing [67]. The isolated county in Minnesota's North Shore (Cook County), which is predominantly rural, is the fifth least-populated county in the state, and the local economy is dependent on tourism and recreation [67]. The three Ohio counties (Van Wert, Paulding, and Henry) are characterized as manufacturing counties, although they contain significant amounts of agricultural lands and significant wind energy development exists in Van Wert and Paulding.

Third, there were a few isolated cases of high-low outlier cases (8) and low-high outlier cases (2), with the former existing within the Lake Michigan Basin of Wisconsin (3), and five counties across the Michigan-Ohio border in the Lake Erie Basin. One of the highlow outlier Wisconsin counties (Menominee) includes the Menominee Indian Reservation, while the two other counties include the city of Milwaukee (Milwaukee County) and Marquette County, both of which are primarily dependent on manufacturing [67]. Another high-low outlier is Wayne County (Detroit), Michigan, indicating that both rural and urban outliers exist in the region. The two low-high outliers lie in Michigan, with one county in the Lake Michigan basin and another in the Lake Huron Basin. There are no clusters or outliers for this theme in the Ontario Basin.

\subsection{Household Composition and Disability}

As a whole, the GLB scores relatively low (between 1.1 and 2.5, with no values above 3 ), in terms of household composition and disability vulnerability. The counties with the highest scores are fairly dispersed across the basins, with a sizable concentration of lower 
scores in the Lake Michigan Basin in Wisconsin, and another grouping of scores in the 1.6-2 range across the Ontario Basin (Figures 4 and 5).

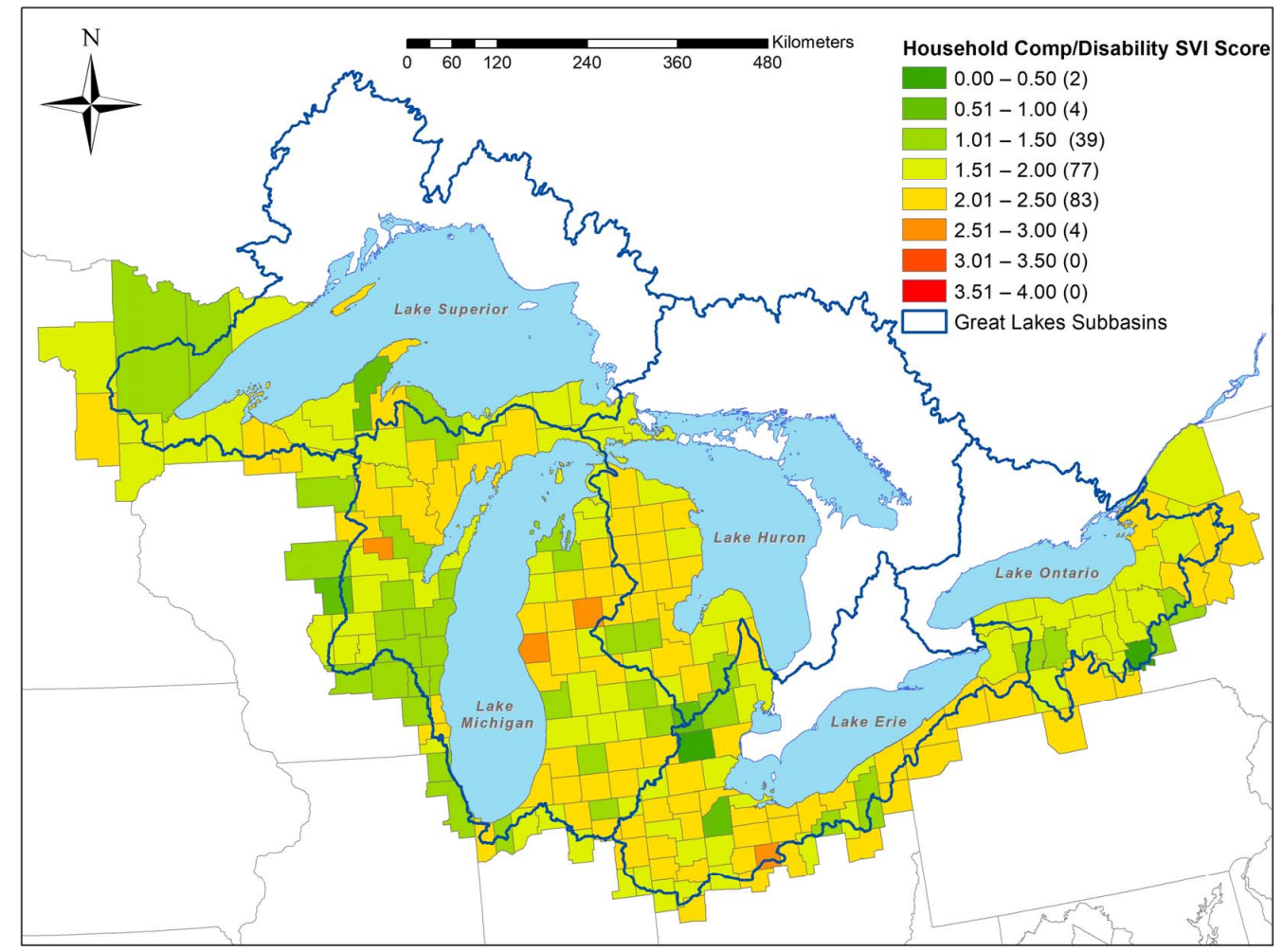

Figure 4. SVI Score for Household Composition and Disability.

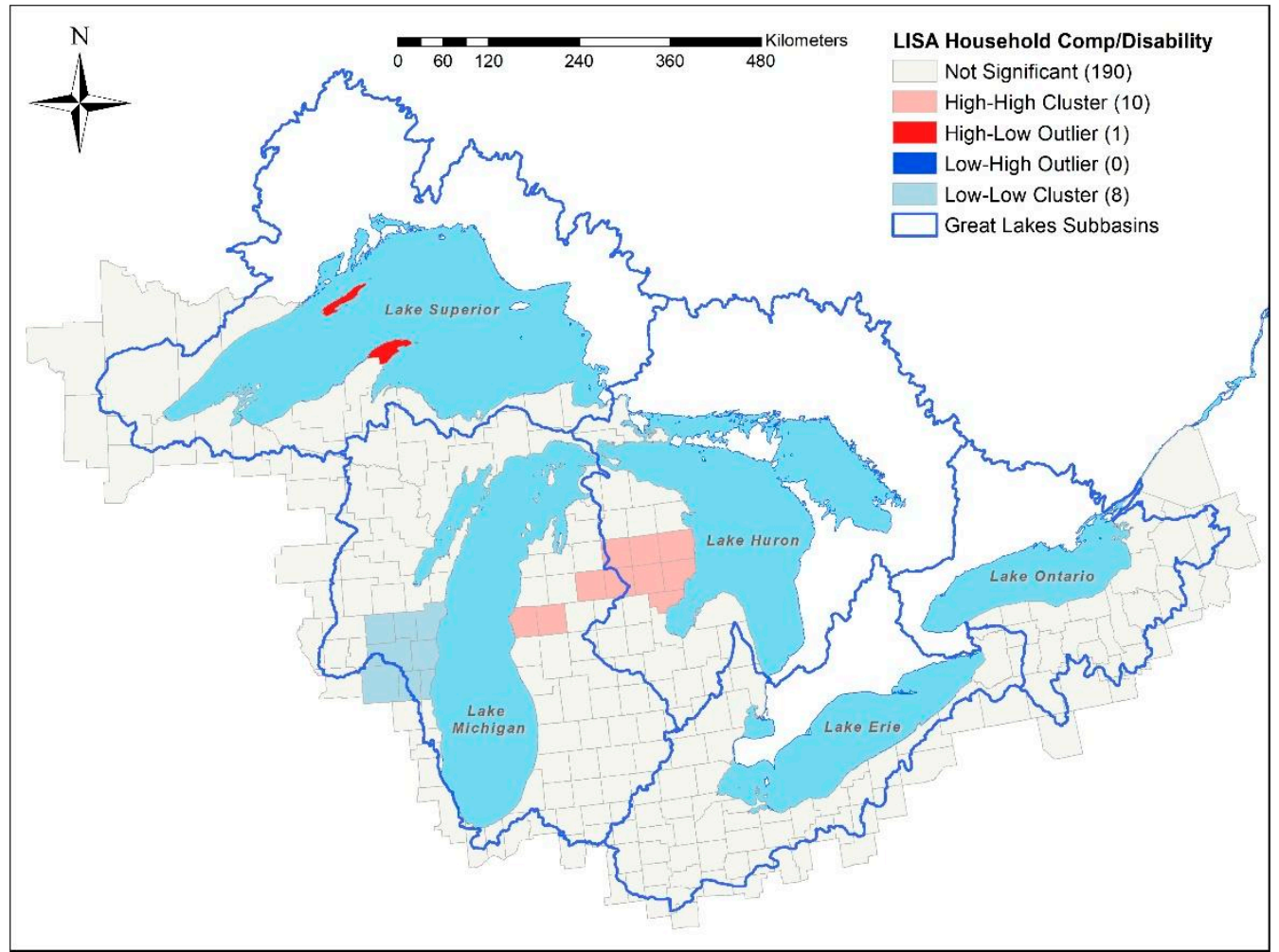

Figure 5. LISA Results for Household Composition and Disability. 
Counties with scores between 2.1-2.5 represent the largest category ( 83 counties), and are mostly scattered across the north shore of Lake Michigan in the state of Wisconsin and overlapping with the northern half of Michigan, previously identified as a high-high cluster of socioeconomic vulnerability. Another grouping of counties in this range extends along Lake Erie's southern shoreline. Higher scores are somewhat less concentrated, but appear in small groups, across the eastern basin of Lake Michigan and the western basin of Lake Huron in the state of Michigan, and stretched across the southern shoreline of Lake Erie, even extending into the southwest corner of the Lake Erie Basin. Only four counties are listed in the 2.6-3 category, with three in the Lake Michigan Basin and one in the Erie Basin. The three counties in the Michigan basin consist of two counties in Western Michigan and one county (Menominee) in Wisconsin.

Results from the LISA analysis for household composition and disability reveal two distinct clusters, with one outlier. A high-high cluster exists in the north-central part of Michigan (10 total counties) spanning across the Lake Huron and Lake Michigan Basins. A low-low cluster also exists in the state of Wisconsin in the Lake Michigan Basin. Both of these trends are consistent with the geographic distribution of socioeconomic social vulnerability. Although there are no low-high outliers, there is one outlier county (Keweenaw) with higher than expected vulnerability scores in the Superior Basin in the northern portion of the Upper Peninsula of Michigan, which also contains Isle Royale Island. There are no clusters or outliers in the Lake Erie or Lake Ontario Basins.

\subsection{Minority Status and Language}

An initial observation is that the region appears fairly homogeneous in terms of minority and language vulnerability at the county level across the basin, except for counties along the southwestern shore of Lake Michigan, between the metropolitan areas of Milwaukee WI and Chicago IL (Figures 6 and 7). However, the spatial scale of this study does not capture diversity at the community or census tract level, particularly for minority communities in rural areas or specific neighborhoods among smaller cities.

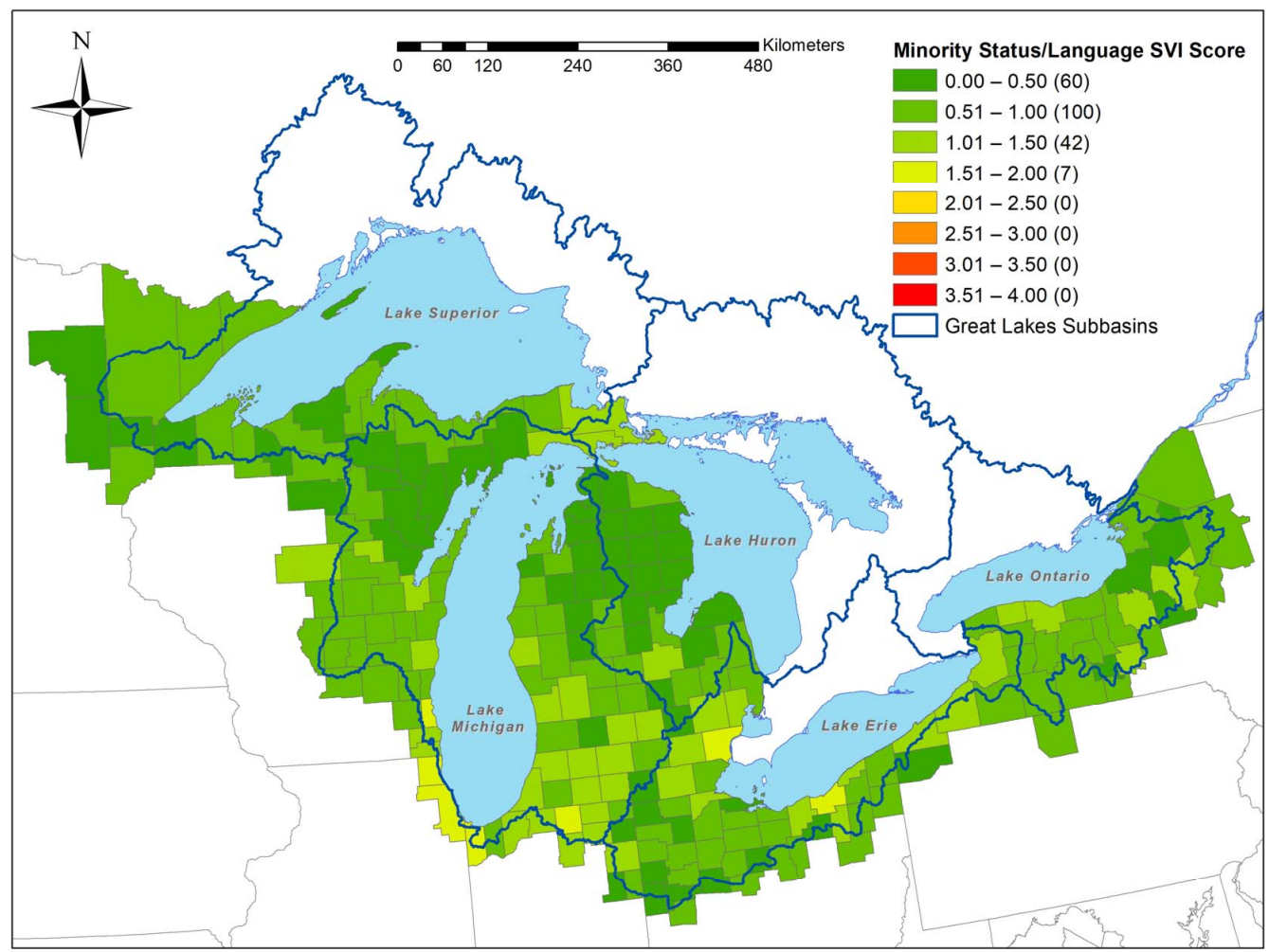

Figure 6. SVI Scores for Minority and Language. 


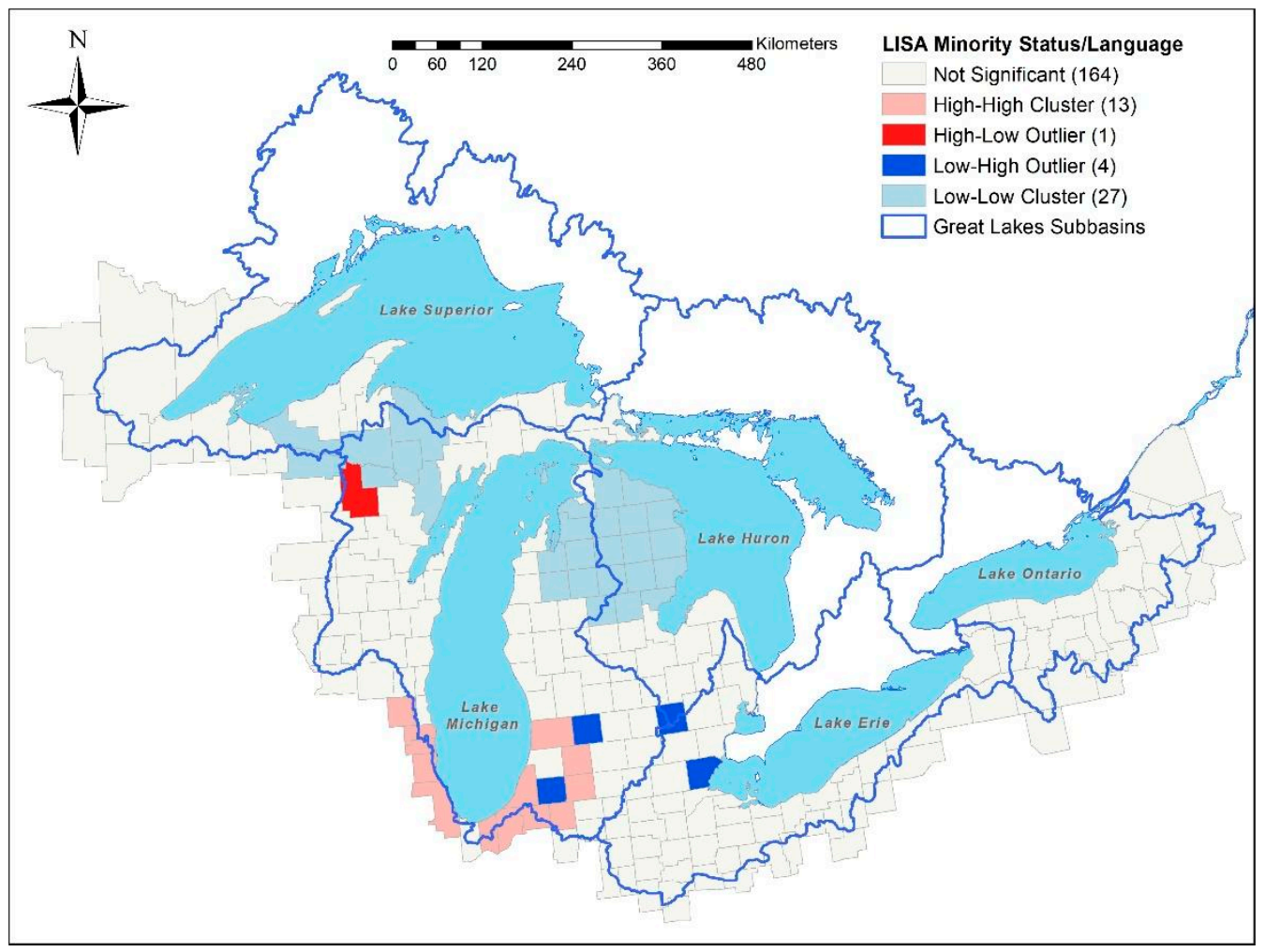

Figure 7. LISA Results for Minority Status and Language.

Despite the lack of significant spatial variation in mapping the SVI scores for this theme in the basin, the exploratory LISA analysis picked up on some of the nuances in the region. First, there are significant low-low clusters along the northern half of Michigan in the Lake Huron and Michigan Basins, and in Northern Wisconsin and the Upper Peninsula of Michigan predominantly in the Lake Michigan Basin, although a few counties extend into the Lake Superior Basin. The Superior-Michigan Basin cluster consists of counties with a non-specialized designation, whereas the Michigan-Huron Basin cluster is a mix of non-specialized, manufacturing, and service-dependent economies [67].

A high-high cluster of vulnerability is found along the southern shoreline of Lake Michigan (13 counties), spanning the states of Wisconsin, Illinois, Indiana, and Michigan. This area represents the sprawling urban centers along the Chicago-Milwaukee corridor, and expands to the east and northeast, incorporating other cities including Gary IN, and Kalamazoo MI. Interestingly, there are four low outlier counties near this high-high cluster, with two counties in the Michigan Basin, one in the Erie and the other at the intersection of the Michigan-Huron-Erie Basins. The two low outliers in the Michigan Basin consist of one county within the Gary, Indiana metropolitan area (Cass County, MI, USA) and one in rural Michigan (Barry County). The outlier in the Erie Basin is Wayne County, Michigan, otherwise known as Detroit, and the low outlier at the intersection of the three basins is Livingston County, home to one of the wealthiest counties in the state on the edge of the Detroit-Warren-Dearborn metropolitan area [4]. There is also one high outlier in the low-low cluster of Northern Wisconsin within the Lake Michigan Basin (Forest County).

\subsection{Housing Type and Transportation}

Housing type and transportation is the highest-rated social vulnerability across the region, with high-value areas in Lake Ontario Basin and the Upper Peninsula of Michigan, and another stretch across the southeastern boundary of the Lake Erie Basin (Figure 8). There appear to be a few hot spots with lower scores, which include two counties in the Lake Superior Basin with scores between 1 and 1.5, with a few pockets in Eastern Wisconsin and Northern Michigan. One county in the Southwest Lake Erie Basin in the 
state of Ohio has the distinction of having a score less than 1, with the highest SVI score for this vulnerability belonging to a county in the Southern Lake Ontario basin.

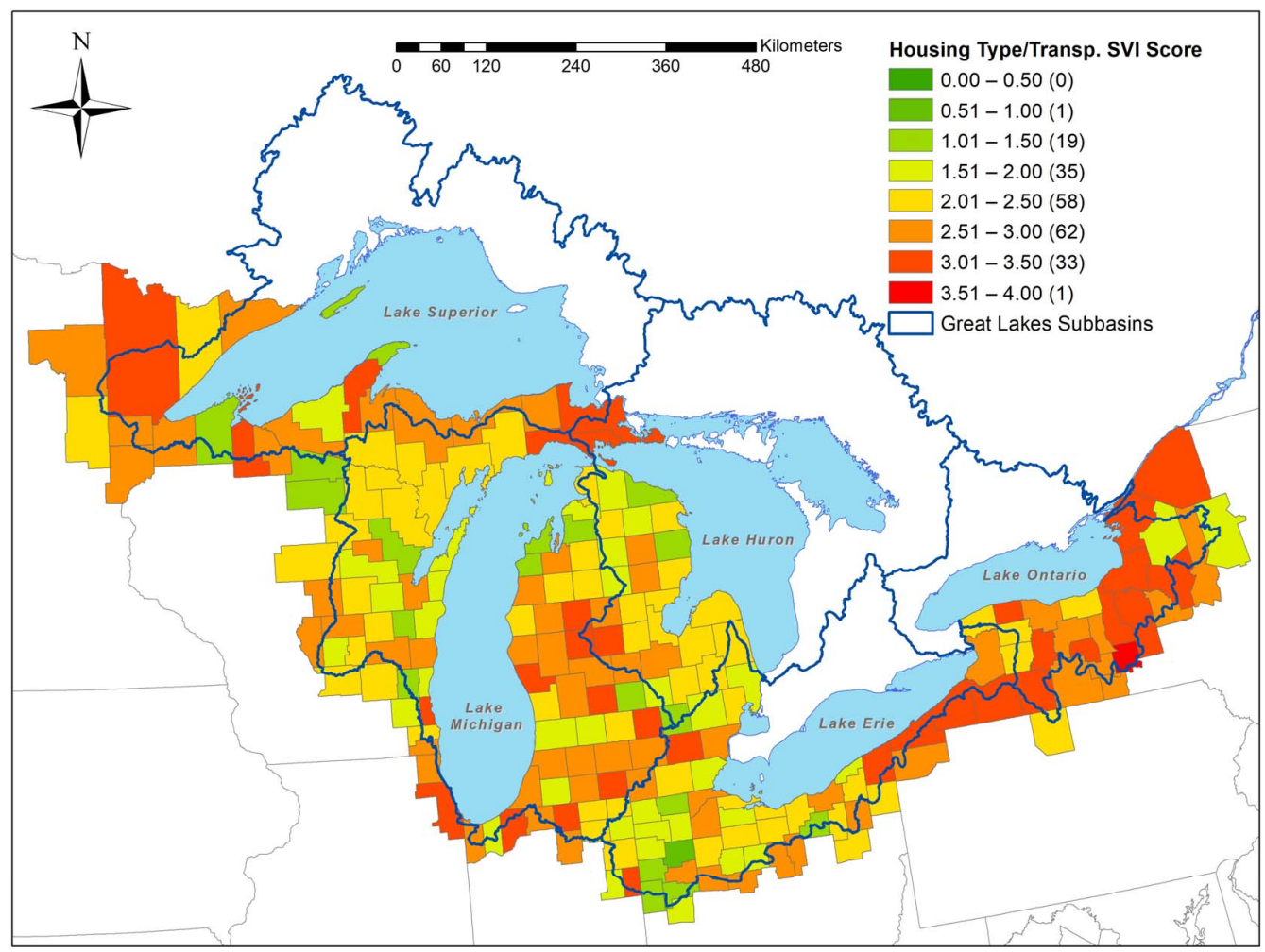

Figure 8. SVI Scores for Housing Type and Transportation.

The LISA results highlight the nuanced differences found across the region for this more widespread vulnerability theme (Figure 9). First, a noticeable cluster of high-high vulnerability exists in the Ontario Basin in the state of New York, with two low outliers near this cluster in Wayne and Lewis Counties, New York. Second, several high outliers exist in the Southwestern Lake Erie Basin in the states of Ohio and Indiana, with two additional counties identified as being high-low outliers in the Huron Basin of Northern Michigan and one county along the western shore of Lake Michigan, where the city of Green Bay is located. Third, two smaller low-low clusters exist next to some of the high-low outliers in the Erie Basin (Northwest Ohio) and three counties spread across the Lake Huron and Lake Michigan basins in the state of Michigan. The Lake Superior Basin does not have any cluster or outlier counties when it comes to housing type and transportation vulnerability.

\subsection{Social Vulnerability by Region}

Overall, the Great Lakes Region is less vulnerable across household composition (theme 2) and minority status and language (theme 3 ) than the rest of the contiguous U.S. The mean composite score for socioeconomic and housing type/transportation vulnerability between GLB and non-GLB counties is not statistically significant, with average scores between 1.63-1.68 and 2.38-2.47, respectively (Figure 10 and Table 2). However, there are statistically significant differences for household composition and minority status, and language vulnerability. Household composition vulnerability for GLB counties is 1.846 and non-GLB counties have an average of $1.996(\mathrm{~F}=12.001 ; p<0.001)$. Similarly, minority status and language vulnerability for GLB counties are 0.743 and non-GLB counties have an average of $0.99(\mathrm{~F}=63.99 ; p<0.001)$. 


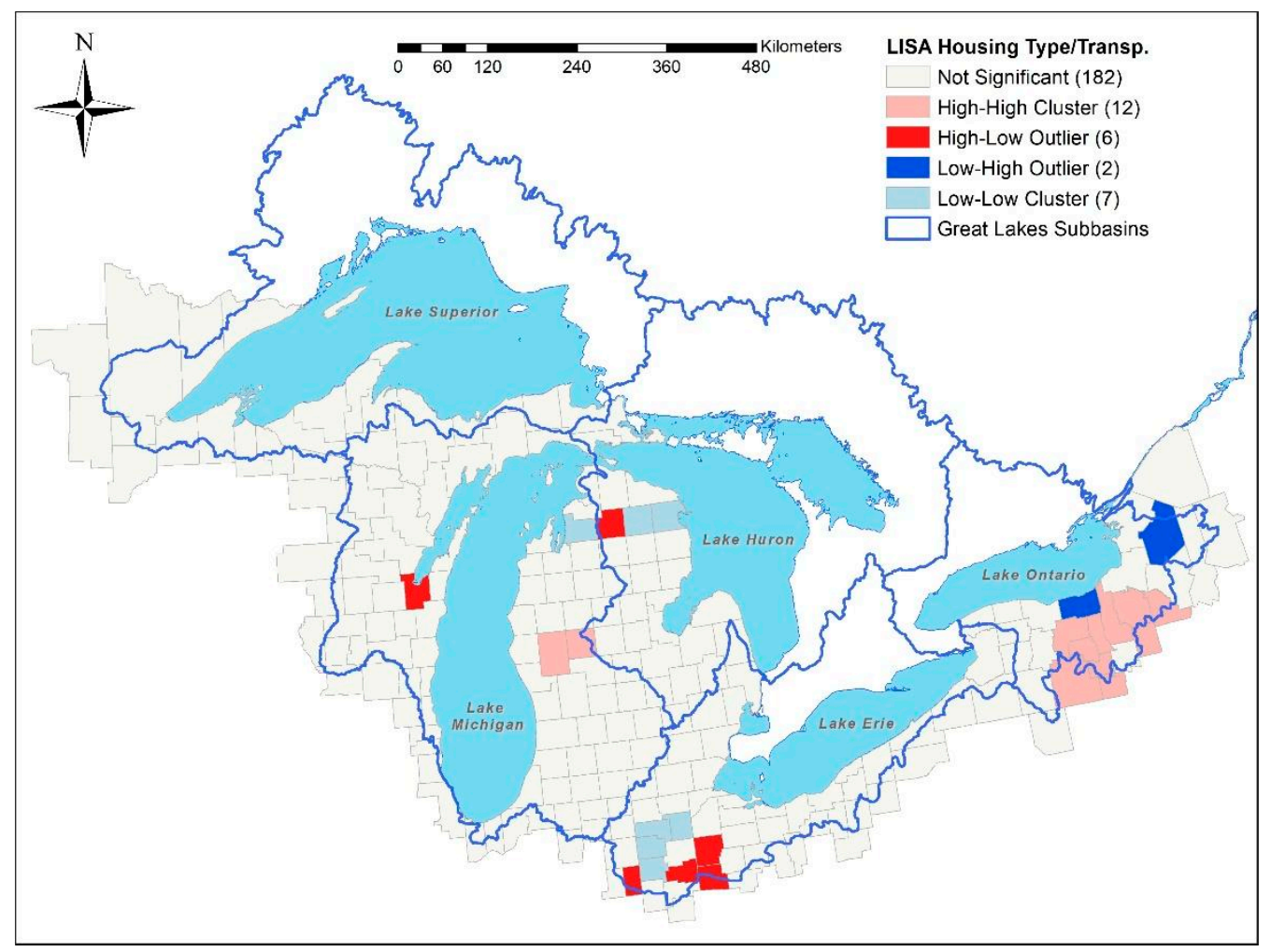

Figure 9. LISA Results for Housing Type and Transportation.

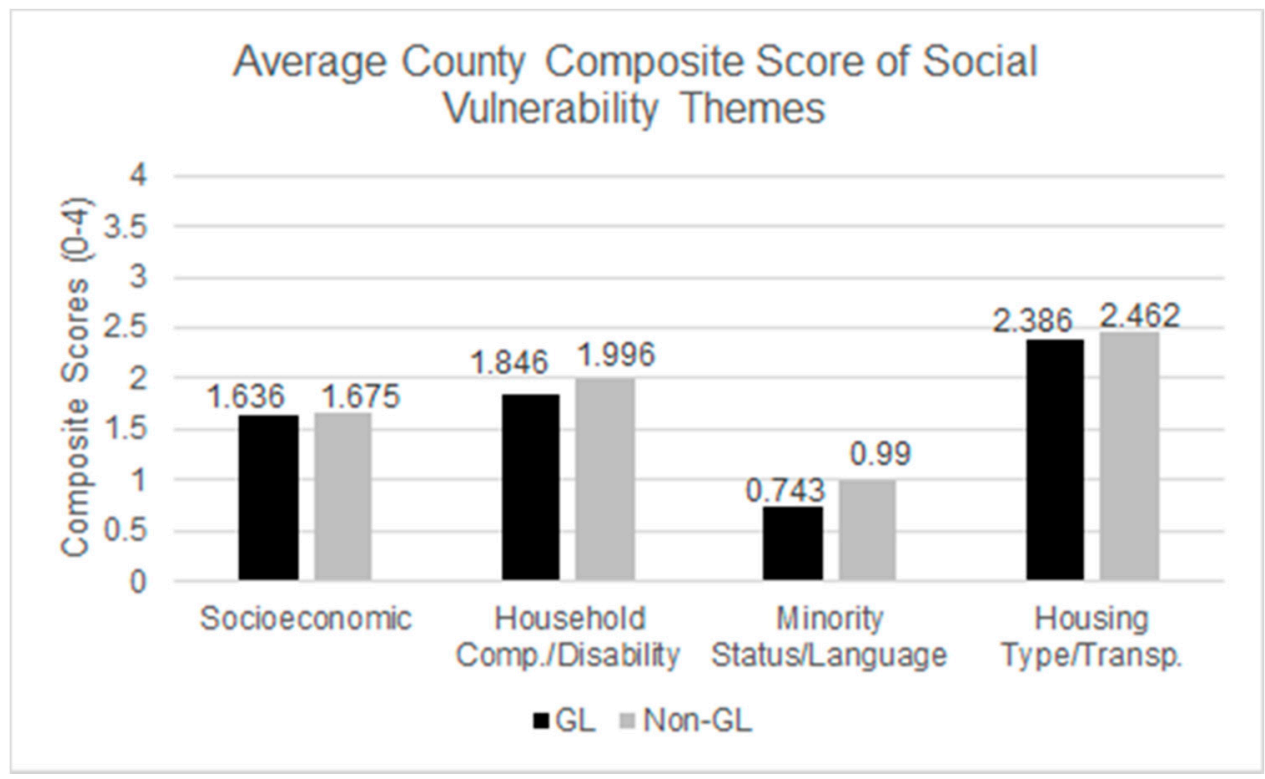

Figure 10. Average County Composite Score of Social Vulnerability Themes.

Table 2. T-test Results between Great Lakes and non-Great Lakes Counties.

\begin{tabular}{ccccc}
\hline SVI Theme & GL (209) & Non-GL (2899) & F & Sig. \\
\hline Socioeconomic Status & 1.636 & 1.675 & 0.249 & 0.913 \\
* Household Composition and Disability & 1.846 & 1.996 & 12.008 & $<0.001$ \\
* Minority Status and Language & 0.743 & 0.99 & 63.994 & $<0.001$ \\
Housing Type and Transportation & 2.386 & 2.462 & 7.384 & 0.124 \\
\hline
\end{tabular}

${ }^{*}$ Difference is significant $(p<0.001)$. 
Household composition and disability SVI scores between the U.S. and the GLB are statistically significant $(\mathrm{f}=12.008 ; p<0.001$ ), where the U.S., in general, has a slightly higher social vulnerability. Second, there are significant differences in the mean composite scores of counties around the third theme of minority status and language, where the rest of the U.S. has slightly higher social vulnerability than the GLB $(f=63.994 ; p<0.001)$. There are no significant differences between the GLB and the rest of the U.S. for socio-economic status and housing type and transportation.

To examine differences in the mean scores of each vulnerability theme within the GLB, average SVI scores for each basin were averaged and compared to examine if there are significant differences at the county level. Figure 11 below shows the mean social vulnerability scores by theme for each lake basin. Table 3 shows mean vulnerability scores along with ANOVA and Tukey's HSD results indicating where significant differences exist between the basins.

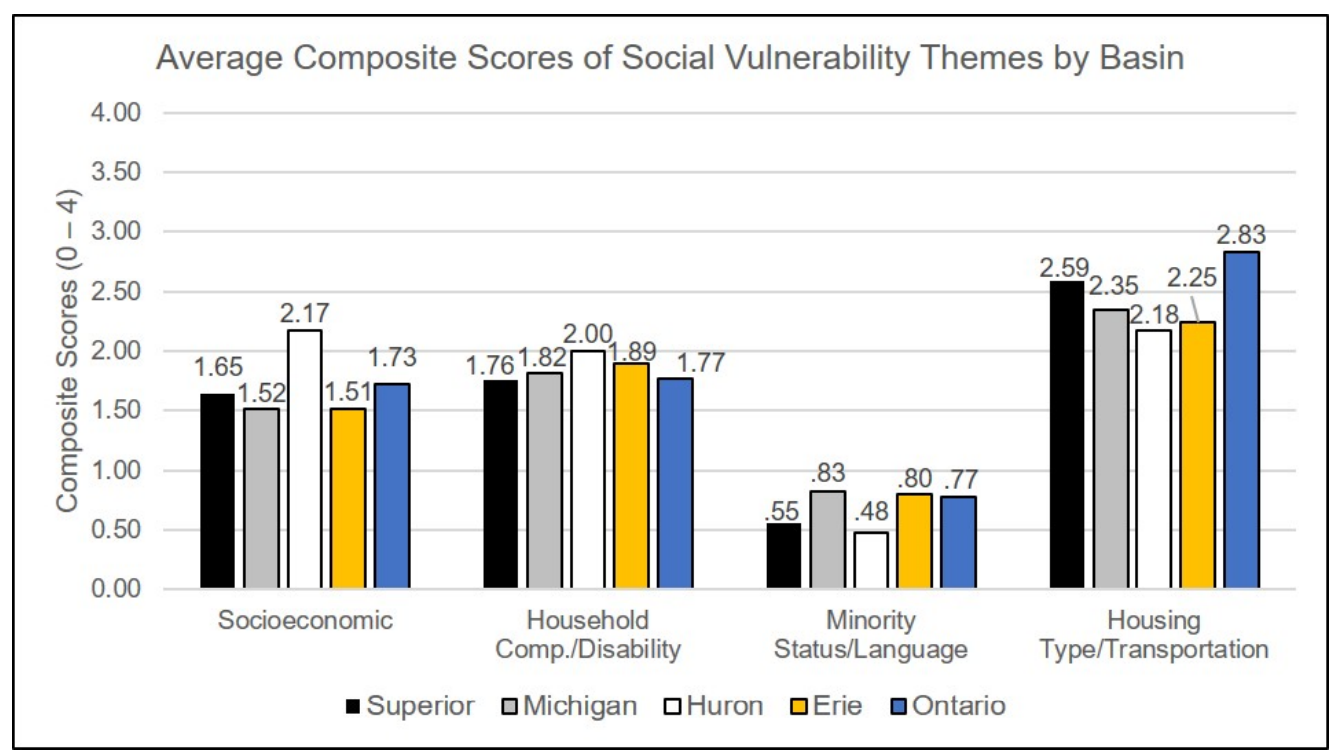

Figure 11. Average Composite Scores of Social Vulnerability Themes by Basin.

Table 3. Social Vulnerability Theme Mean by Lake Basin with Tukey's HSD.

\begin{tabular}{|c|c|c|c|c|c|c|c|c|c|}
\hline SVI Theme & Superior & Michigan & Huron & Erie & Ontario & $\mathbf{F}$ & Sig. & Diff. * & Sig. \\
\hline Socioeconomic Status & 1.65 & 1.52 & 2.17 & 1.51 & 1.73 & 5.09 & $<0.001$ & $\begin{array}{l}\mathrm{H} \neq \mathrm{M} \\
\mathrm{H} \neq \mathrm{E}\end{array}$ & $\begin{array}{l}<0.001 \\
<0.001\end{array}$ \\
\hline $\begin{array}{l}\text { Household Composition } \\
\text { and Disability }\end{array}$ & 1.76 & 1.82 & 2.00 & 1.89 & 1.77 & 1.63 & 0.168 & ns & Ns \\
\hline $\begin{array}{l}\text { Minority Status } \\
\text { and Language }\end{array}$ & 0.55 & 0.83 & 0.48 & 0.80 & 0.77 & 6.75 & $<0.001$ & $\begin{aligned} M & \neq S \\
M & \neq \mathrm{H} \\
\mathrm{H} & \neq \mathrm{E} \\
\mathrm{H} & \neq \mathrm{O}\end{aligned}$ & $\begin{array}{c}0.017 \\
<0.001 \\
0.002 \\
0.021\end{array}$ \\
\hline $\begin{array}{c}\text { Housing Type } \\
\text { and Transportation }\end{array}$ & 2.59 & 2.35 & 2.18 & 2.25 & 2.83 & 6.50 & $<0.001$ & $\begin{array}{l}\mathrm{O} \neq \mathrm{M} \\
\mathrm{O} \neq \mathrm{H} \\
\mathrm{O} \neq \mathrm{E}\end{array}$ & $\begin{array}{c}0.002 \\
<0.001 \\
<0.001\end{array}$ \\
\hline
\end{tabular}

* $\mathrm{S}$ = Superior; $\mathrm{M}=$ Michigan; $\mathrm{H}=$ Huron; $\mathrm{E}=$ Erie; $\mathrm{O}=$ Ontario.

Socioeconomic vulnerability is highest in the Huron Basin (2.17), followed by Ontario (1.73), Superior (1.65), Michigan (1.52), and Erie (1.51). The Huron Basin and the Michigan Basin are significantly different $(p<0.001)$, as well as the differences between the Huron and Erie Basins $(p<0.001)$. The Superior and Ontario Basin were not significantly different from other basins, but have means that indicate more vulnerability for socioeconomic 
vulnerability than the Michigan and Erie Basins. There are no significant differences between the vulnerability scores for household composition and disability. However, it is interesting to note that the Huron Basin has the highest average score for this vulnerability (2), followed by Erie (1.89), Michigan (1.82), Ontario (1.77), and Superior (1.72).

Minority status and language vulnerability have the most significant differences across the GLB, but it should be noted that this theme also had the lowest vulnerability scores in general across the region, ranging from 0.83 to 0.48 across the GLB. First, the Michigan Basin (0.83) has a higher vulnerability score for minority status and language than both the Superior $(0.55 ; p=0.017)$ and Huron $(0.48 ; p<0.001)$ Basins. Second, the Lake Huron Basin had lower vulnerability scores than both the Erie $(0.80 ; p=0.002)$ and Ontario (0.77; $p=0.021$ ) Basins. In both cases, the Huron-Michigan basins appear to be more vulnerable for this theme than the rest of the GLB.

Housing type and transportation vulnerability represent the theme with the highest average scores across the GLB. The most vulnerable basin for housing type and transportation is Ontario (2.83), followed by Superior (2.59), Michigan (2.35), Erie (2.25), and Huron (2.18). The mean score for the Ontario Basin for this theme is significantly higher than the Michigan $(p=0.002)$, Huron $(p<0.001)$, and Erie $(p<0.001)$ Basins.

\section{Discussion}

While this study has found that the GLB is not as socially vulnerable as other parts of the U.S., significant inter-basin variability exists and requires analysis for effective, place-based strategies that enhance resiliency (Figure 12).

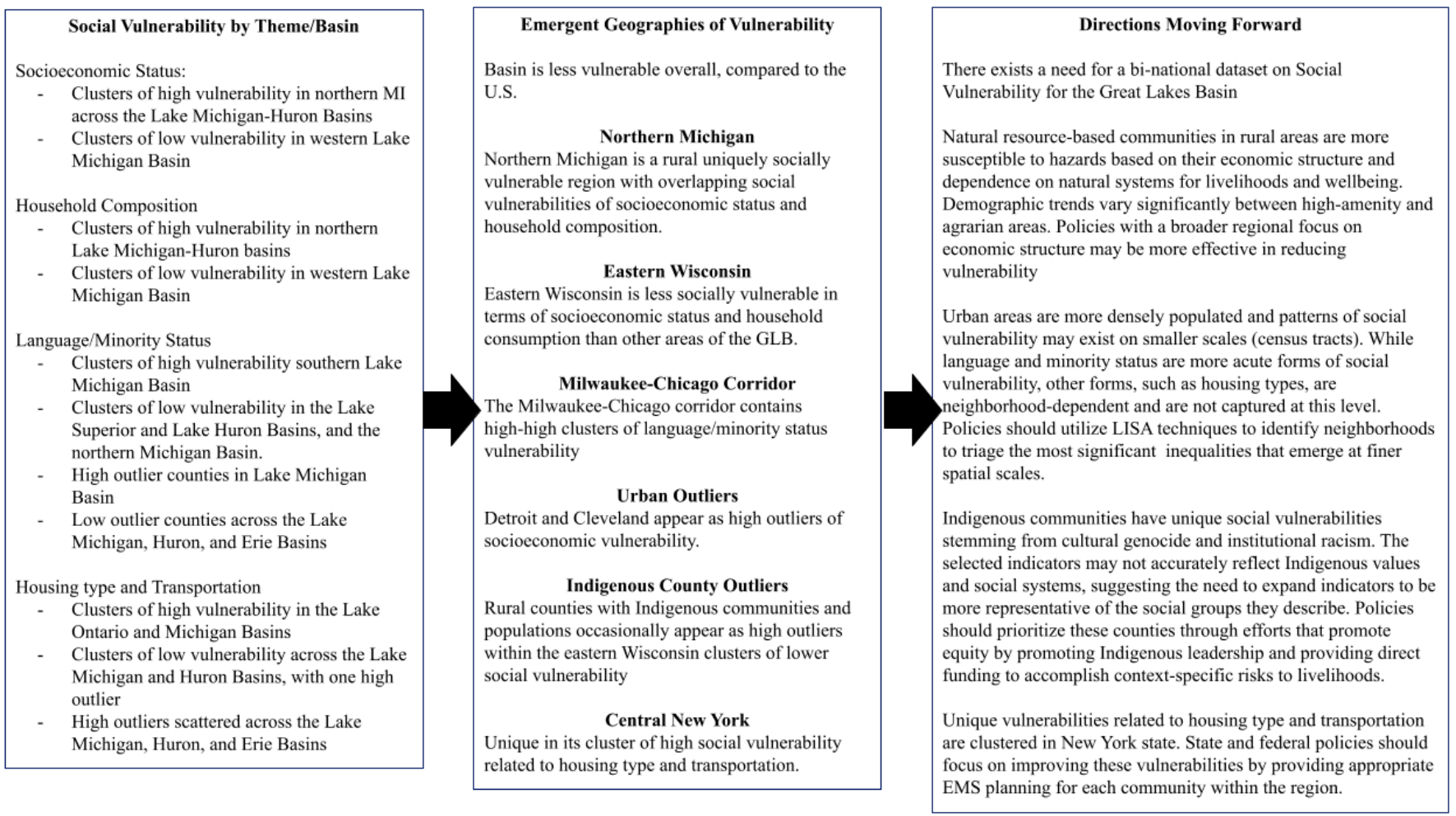

Figure 12. A flow diagram of findings, vulnerable geographies, and policy considerations.

Specifically, Social Vulnerability Index (SVI) scores indicate that from a socioeconomic perspective, social vulnerability is highest in the Lake Huron Basin. The vulnerability associated with household composition and disabilities are fairly well dispersed across the basin, and no significant differences across the basins exist. However, a cluster of higher vulnerability again exists across Michigan between Lake Huron and Lake Michigan. Overall, vulnerability as a product of language and minority status is low, but significant differences 
do exist across the basin, with the Huron and the Superior Basins being significantly lower than the rest of the region. This may be a reflection of a rather homogeneous population when data is aggregated at the county level. Finally, while mean scores were relatively higher for the theme of housing type and transportation vulnerability, the Lake Ontario basin stands out as being significantly higher than the Michigan, Huron, or Erie basin, and although not statistically significant, has a higher average than the Superior Basin.

There are several notable themes and spatial patterns of social vulnerability across the GLB revealed in this study. Comparing mean SVI scores across basins helps identify meaningful differences across the basins, and this has identified important trends such as the Lake Huron Basin being more socioeconomically vulnerable than other basins, and the Lake Ontario basin being more vulnerable in terms of housing type and transportation. Interestingly, there are no significant differences across the basins for the social vulnerability theme of household composition (Table 3); however, cluster-outlier analysis reveals clustering of high and low household composition. Additionally, the significance of the socioeconomic vulnerability of the Lake Huron Basin may be a result of the largely rural geography of the basin, influenced by measures such as per capita income where the cost of living may be cheaper in some cases. This suggests that while both comparing means across basins and utilizing exploratory spatial techniques can provide different insights into the distribution of social vulnerability, it highlights how social landscapes stretch across ecological boundaries, complicating the incorporation of the social landscape in ecological studies at the epistemological and methodological levels.

Exploratory mapping techniques advance this understanding by identifying specific spatial patterns that provide a better understanding of the spatial distribution of vulnerability. This study demonstrates the usefulness of this approach by highlighting interesting findings not observable with a-spatial statistical techniques.

First, the area of Northern Michigan spanning the Michigan-Huron basin appears to be one of the more socially vulnerable regions within the GLB. This is confirmed by the cluster and outlier analysis that suggests that both socioeconomic and household composition vulnerabilities overlap here, with a smaller high-high cluster for housing type and transportation. Overall, these results suggest that the overlapping socioeconomic, household composition and disability vulnerabilities, in Michigan across both the Lake Huron Basin and Lake Michigan Basin highlights one geography that is particularly socially vulnerable. Additionally, this conglomerate highlights a largely rural area, shedding light on how the spatial patterns of rural social vulnerability can look different than the spatially concentrated patterns found in neighborhoods within larger cities. This demonstrates that social vulnerability may also have urban-rural dimensions within the GLB that shape the geographic pattern of the vulnerability. The widespread social vulnerability associated with rurality and natural-resource-based communities is also associated with decades of decline and cyclical poverty [17].

Second, and relatedly, the string of counties that represent the Milwaukee-Chicago corridor is notable as a vulnerable region but has a different spatial pattern than the more rural area of Northern Michigan. First, it is the only high-high cluster area identified in assessing the social vulnerability of minority status and language. Second, there appear to be geographic shifts in SVI scores based on Figures 2, 4 and 8, depicting the SVI scores for socioeconomic, household composition, and housing type/transportation vulnerability respectively, that are not always identified as significant in a LISA analysis. However, a closer examination of the LISA results for socioeconomic vulnerability (Figure 3) shows Milwaukee County identified as a high-low outlier just south of a low-low cluster, and a low-low cluster for household composition and disability that starts just north of this county. Figure 8 shows this corridor as containing a high level of housing type and transportation vulnerability, but the cluster-outlier analysis (Figure 9) does not identify the area as a significantly differentiated neighborhood.

Third, the social vulnerability theme of minority status and language demonstrates the unique vulnerability of the Southern Lake Michigan Basin. Although average scores of 
this third theme are low and do not show much range, the Lake Superior and Huron Basins appear less vulnerable than the rest of the Great Lakes. Cluster-outlier analysis results show where the Michigan basin is most vulnerable, with a high-high cluster stretching from the Chicago MSA of Illinois into the southwestern portion of Michigan, and significant lowlow clusters in Northern Michigan and Northern Wisconsin. The four low-high counties in Michigan represent counties with significant cities (Grand Rapids, Flint, Kalamazoo, Detroit), an interesting finding given the association between urban areas as a place with more diversity and non-English use. Interestingly, the same general area identified as being a high-high cluster for socioeconomic and household composition in Northern Michigan appears less vulnerable to minority status and language vulnerability. This may be the result of a more homogeneous, native-English speaking population existing in the more rural parts of Michigan. While several Indigenous communities exist across this region, they are often historically undercounted and underrepresented in the ACS surveys used to construct the SVI [68].

Fourth, there are several counties with Indigenous populations in Wisconsin that appear as high-low outliers for the social vulnerability themes of socioeconomic status (Menominee County) and minority status and language (Forest County). Menominee County hosts the Menominee Reservation and Forest County is home to two Indigenous communities, the Forest County Potawatomi Community and the Sokaogon Chippewa Community. Their high-low outlier status indicates that the surrounding counties consist of a neighborhood with significantly higher scores than random chance alone, demonstrating how populations can find themselves with heightened social vulnerabilities even when surrounded by more resilient geographies, by natural forces, or otherwise [69]. In other cases, the cluster-outlier analysis may not find a statistically significant outlier, but as is the case for the social vulnerability of household composition and transportation (Figure 3), the Native-majority Menominee County stands out as one of only four counties with SVI scores in the range of 2.6-3. Additionally, the use of ACS data may be limited in accurately reflecting these places, and this approach may also limit other assets available to these places that serve to reduce vulnerability not being measured.

Finally, the theme of housing type and transportation has a unique spatial pattern that stands out compared to the other three social vulnerability themes, both in the widespread nature of this vulnerability (Figures 8 and 10) and the clustering/outlier patterns across the basin (Figure 9). The high-high cluster in the Ontario Basin highlights a geography that was not identified as particularly vulnerable according to other themes. Additionally, a somewhat unique cluster emerged in Michigan that just lightly overlaps with the high-high socioeconomic cluster for the same region. Along with the scattered high-low counties along Ohio and Indiana, a few isolated outliers exist in Wisconsin and Northern Michigan as well. These counties may be the locations of the nearest regional town that provides medical services, prison populations, and/or apartment complexes, which can significantly influence the SVI scores. Simply put, rural areas may only have one town in a neighboring county where these services are available, and as a result, they draw more multi-unit housing structures and populations living in group quarters.

\section{Limitations}

Several limitations should be considered. First, while using generalized indicators across the community allows for statistical comparisons, the specific indicators used in the creation of the social vulnerability indices can vary in the degree to which they serve as a vulnerability [70]. This study utilizes the CDC SVI for the sake of consistency, but regional planners and policymakers need to identify and consider the unique local indicators they use to assess vulnerability and direct their time and resources that make sense given the specific community context.

Second, the spatial scale used in this study is limited in its ability to assess minority status and language as a social vulnerability, particularly involving inner-city and Indigenous populations. County-level analysis limits the finer spatial scale needed (census tract) 
to understand spatial inequality in more dense urban areas [71]. Furthermore, the data used relies on a methodology that underrepresents and undercounts Indigenous communities in and around the GLB, making the approach limited in the representation of this particular social group. This has the potential to further exacerbate inequalities and has the potential to under-assess community resilience and vulnerability $[68,69]$. Additionally, sociodemographic data on Indigenous communities can miss other culturally relevant data to understand the social context of place, and they are frequently used to paint a picture of deficit which is not always helpful for producing resilience.

Third, this study is U.S.-centric. U.S. databases are more easily accessible and available for this particular analysis. Additionally, the geopolitical units in Canada are significantly different than the state-county-township-town system in the U.S. from both a governance and a spatial perspective. Even finding up-to-date demographic information for the region is difficult.

\section{Conclusions}

Understanding the patterns of social vulnerability across relevant ecological boundaries helps incorporate the social landscape into natural resource management, risk management, community development, and emergency planning and preparedness. Using the CDC'S SVI [4], this study explores and compares four themes of social vulnerability while highlighting the unique geographies that represent clusters of vulnerability and resilience, as well as outliers that warrant further attention. While there is still debate on the selection of the indicators used to measure the concept [17,70], an understanding of the spatial distribution of any indicator improves understanding of the spatial patterns of social vulnerability.

Results reveal a region where social vulnerability is elevated for swaths of rural Michigan as multiple clusters overlap in the state surrounded by the Great Lakes. Eastern Wisconsin appears to be more resilient than other areas but has a few outliers that emerge with the location of Indigenous communities, suggesting that this territory of resilience is unequally distributed among tribal and non-tribal communities. The Chicago-Milwaukee corridor around Lake Michigan also reveals an area of vulnerability defined by minority status and language, but no other social vulnerability exists, highlighting nuances between rural and urban social vulnerability. Furthermore, the Lake Ontario basin was not identified as particularly vulnerable except for the theme of housing type and transportation, in which it was the most vulnerable region and had significant clustering, suggesting that specific social vulnerabilities cluster around particular regions (Northern Michigan, Eastern Wisconsin, Western and Central New York). This demonstrates a need for continued work in the spatial exploration of social vulnerability and multiple scales to tease out what makes a region of communities more vulnerable than another.

Future research assessing social vulnerability is critical to identifying the geography of vulnerability across the basin, and several ideas stem from this work. First, there exists a need to build a comprehensive, bi-national social vulnerability dataset for the region for an appropriate understanding of social vulnerability for the entire basin. Second, there needs to be more effort in mapping physical infrastructure and its characteristics with socio-demographic data. As the social landscape of risk grows with interdisciplinary projects, the spatial relationships between physical structures and social groups must be better understood to adequately address environmental justice issues in the region. Moving to address future issues related to infrastructure without maintaining the current (and degrading) infrastructure of older urban and rural communities will ensure environmental hazards from extreme weather events will create significant barriers to resilience and community capacity building. Finally, more effort is needed to identify and alleviate highlow outliers and understand the governance processes that lead to these developments. This study reveals that some of these outliers are associated with the presence of Indigenous communities, but other outliers exist where such communities are no longer present. 
Author Contributions: Conceptualization, J.T.F. and R.D.B., Methodology J.T.F., Investigation J.T.F. and R.D.B., Formal Analysis J.T.F., Validation J.T.F., Writing J.T.F. and R.D.B., Writing-Review and Editing R.D.B. and J.T.F. All authors have read and agreed to the published version of the manuscript.

Funding: This research was funded by the National Science Foundation, grant number 1940128.

Data Availability Statement: The data presented in this study are openly available from the CDC/ATSDR at https://www.atsdr.cdc.gov/placeandhealth/svi/data_documentation_download. html (accessed on 28 June 2021).

Conflicts of Interest: The authors declare no conflict of interest. The funders had no role in the design of the study; in the collection, analyses, or interpretation of data; in the writing of the manuscript, or in the decision to publish the results.

\section{References}

1. Méthot, J.; Huang, X.; Grover, H. Demographics and societal values as driver of change in the Great Lakes-St. Lawrence River basin. J. Great Lakes Res. 2015, 41, 30-44. [CrossRef]

2. Laurent, K.L.; Friedman, K.B.; Krantzberg, G.; Scavia, D.; Creed, I.F. Scenario analysis: An integrative and effective method for bridging disciplines and achieving a thriving Great Lakes-St. Lawrence River basin. J. Great Lakes Res. 2015, 41, 12-19. [CrossRef]

3. Bartolai, A.M.; He, L.; Hurst, A.E.; Mortsch, L.; Paehlke, R.; Scavia, D. Climate change as a driver of change in the Great Lakes St. Lawrence River Basin. J. Great Lakes Res. 2015, 41, 45-58. [CrossRef]

4. Centers for Disease Control and Prevention's (CDC) Social Vulnerability Index (SVI). Agency for Toxic Substances and Disease Registry. Geospatial Research, Analysis, and Services Program. Database U.S. 2018. Available online: https://www.atsdr.cdc. gov/placeandhealth/svi/data_documentation_download.html (accessed on 13 May 2021).

5. Colburn, L.L.; Jepson, M.; Weng, C.; Sears, T.; Weiss, J.; Hare, J.A. Indicators of climate change and social vulnerability in fishing dependent communities along the Eastern and Gulf Coasts of the United States. Mar. Policy 2016, 74, 323-333. [CrossRef]

6. Wood, N.J.; Burton, C.G.; Cutter, S.L. Community variations in social vulnerability to Cascadia-related tsunamis in the U.S. Pacific Northwest. Nat. Hazards 2010, 52, 369-389. [CrossRef]

7. Morrow, B.H. Identifying and mapping community vulnerability. Disasters 1999, 23, 1-18. [CrossRef]

8. Rifat, S.A.A.; Liu, W. Measuring community disaster resilience in the conterminous coastal United States. ISPRS Int. J. Geo-Inf. 2020, 9, 469. [CrossRef]

9. Flanagan, B.E.; Hallisey, J.E.; Adams, E.; Lavery, A. Measuring community vulnerability to natural and anthropogenic hazards: The Centers for Disease Control and Prevention's Social Vulnerability Index. J. Environ. Health 2018, 80, 34-36. Available online: https:/ / www.ncbi.nlm.nih.gov/pmc/articles/PMC7179070/ (accessed on 13 May 2021).

10. Adger, W.N. Vulnerability. Glob. Environ. Chang. 2006, 16, 268-281. [CrossRef]

11. Matarrita-Cascante, D.; Trejos, B.; Qin, H.; Joo, D.; Debner, S. Conceptualizing community resilience: Revisiting conceptual distinctions. Community Dev. J. 2017, 48, 105-123. [CrossRef]

12. Otto, I.M.; Reckien, D.; Reyer, C.P.O.; Marcus, R.; Le Masson, V.; Jones, L.; Norton, A.; Serdeczny, O. Social vulnerability to climate change: A review of concepts and evidence. Reg. Environ. Chang. 2017, 17, 1651-1662. [CrossRef]

13. Cutter, S.L.; Boruff, B.J.; Shirley, W.L. Social vulnerability to environmental hazards. Soc. Sci. Q. 2003, 84, 242-261. [CrossRef]

14. Emrich, C.T.; Cutter, S.L. Social vulnerability to climate-sensitive hazards in the southern United States. Weather Clim. Soc. 2011, 3, 193-208. [CrossRef]

15. Spielman, S.E.; Tuccillo, J.; Folch, D.C.; Schweikert, A.; Davies, R.; Wood, N.; Tate, E. Evaluating social vulnerability indicators: Criteria and their application to the Social Vulnerability Index. Nat. Hazards 2020, 100, 417-436. [CrossRef]

16. Tate, E.; Rahman, A.; Emrich, C.T.; Sampson, C.C. Flood exposure and social vulnerability in the United States. Nat. Hazards 2021, 106, 435-457. [CrossRef]

17. Flanagan, B.E.; Hallisey, E.; Sharpe, J.D.; Merzlufft, C.E.; Grossman, M. On the validity of validation: A commentary on Rufat, Tate, Emrich, and Antolini's 'How valid are social vulnerability models'? Ann. Assoc. Am. Geogr. 2021, 111. [CrossRef]

18. Khajehei, S.; Ahmadalipour, A.; Shao, W.; Mordakhani, H. A place-based assessment of flash flood hazard and vulnerability in the contiguous United States. Sci. Rep. 2020, 10, 448. [CrossRef]

19. Adger, W.N.; Kelly, P.M. Social vulnerability to climate change and the architecture of entitlements. Mitig. Adapt. Strateg. Glob. Chang. 1999, 4, 253-266. [CrossRef]

20. Eriksen, C.; Simon, G.L.; Roth, F.; Lakhina, S.J.; Wisner, B.; Adler, C.; Thomalla, F.; Scolobig, A.; Brady, K.; Brundl, M.; et al. Rethinking the interplay between affluence and vulnerability to aid climate change adaptive capacity. Clim. Chang. 2020, 162, 25-39. [CrossRef]

21. Freudenburg, W.R.; Gramling, R. Natural resources and rural poverty: A closer look. Soc. Nat. Res. 1994, 7, 5-22. [CrossRef]

22. Peluso, N.L.; Humphrey, C.R.; Fortmann, L.P. The rock, the beach, and the tidal pool: People and poverty in natural resourcedependent areas. Soc. Nat. Res. 1994, 7, 23-38. [CrossRef] 
23. McLellan, S.L.; Hollis, E.J.; Depas, M.M.; Van Dyke, M.; Harris, J.; Scopel, C.O. Distribution and fate of Escherichia coli in Lake Michigan following contamination with urban stormwater and combined sewer overflows. J. Great Lakes Res. 2007, 33, 566-580. [CrossRef]

24. Patz, J.A.; Vavrus, S.J.; Uejio, C.K.; McLellan, S.L. Climate change and waterborne disease risk in the Great Lakes Region of the U.S. Am. J. Prev. Med. 2008, 35, 451-458. [CrossRef] [PubMed]

25. Cutter, S.L.; Finch, C. Temporal and spatial challenges in social vulnerability to natural hazards. Proc. Natl. Acad. Sci. USA 2008, 105, 2301-2306. [CrossRef] [PubMed]

26. Lehnert, E.A.; Wilt, G.; Flanagan, B.; Hallisey, E. Spatial exploration of the CDC's Social Vulnerability Index and heat-related health outcomes in Georgia. Int. J. Disaster Risk Reduct. 2020, 46, 101517. [CrossRef]

27. Eriksen, S.H.; Kelly, P.M. Developing credible vulnerability indicators for climate adaptation policy assessment. Mitig. Adapt. Strateg. Glob. Chang. 2006, 12, 495-524. [CrossRef]

28. De Vet, E.; Eriksen, C.; Booth, K.; French, S. An unmitigated disaster: Shifting from response and recovery to mitigation for an insurable future. Int. J. Disaster Risk Sci. 2019, 10, 179-192. [CrossRef]

29. IPCC. Climate Change 2007: Impacts, Adaptation and Vulnerability; Contribution of Working Group 2 to the Fourth Assessment Report of the Intergovernmental Panel on Climate Change; Parry, M.L., Canziani, O.F., Palutikof, J.P., van der Linden, P.J., Hanson, C.E., Eds.; Cambridge University Press: Cambridge, UK, 2007; 976p.

30. Younus, M.A.F.; Kabir, M.A. Climate change vulnerability assessment and adaptation of Bangladesh: Mechanisms, notions and solutions. Sustainability 2018, 10, 4286. [CrossRef]

31. Flanagan, B.E.; Gregory, E.W.; Hallisey, E.J.; Heitgerd, J.L.; Lewis, B. A social vulnerability index for disaster management. J. Homel. Secur. Emerg. Manag. 2011, 8. Available online: http://www.bepress.com/jhsem/vol8/iss1/3 (accessed on 15 May 2021). [CrossRef]

32. Gold, A.; Pendall, R.; Treskon, M. Demographic Change in the Great Lakes Region: Recent Population Trends and Possible Futures; Metropolitan Housing and Communities Policy Center: Washington, DC, USA, 2018.

33. Gregg, R.M.; Feifel, K.M.; Kershner, J.M.; Hitt, J.I. The State of Climate Change Adaptation in the Great Lakes Region; Ecoadapt: Bainbridge Island, WA, USA, 2012; Available online: https:// www7.nau.edu/itep/main/iteps/ORCA/3710_ORCA.pdf (accessed on 15 May 2021).

34. Friedman, K.B.; Laurent, K.L.; Kranzberg, G.; Scavia, D.; Creed, I.F. The Great Lakes Futures Project: Principles and policy recommendations for making the lakes great. J. Great Lakes Res. 2015, 41, 171-179. [CrossRef]

35. Melillo, J.; Yohe, G.W. Climate Change Impacts in the United States: The Third National Climate Assessment; U.S. Global Change Research Program: Washington, DC, USA, 2014. [CrossRef]

36. Wuebbles, D.; Cardinale, B.; Cherkauer, K.; Davidson-Arnott, R.; Hellmann, J.; Infante, D.; Johnson, L.; de Loe, R.; Lofgren, B.; Packman, A.; et al. An Assessment of the Impacts of Climate Change on the Great Lakes. Environmental Law \& Policy Center 2019. Available online: https:/ / cardinale.seas.umich.edu/wp-content/uploads/2020/06/Wuebbles-et-al-Great-Lakes-ClimateChange-Report.pdf (accessed on 13 May 2021).

37. Sterner, R.W.; Keeler, B.; Polasky, S.; Poudel, R.; Rhude, K.; Rogers, M. Ecosystem services of Earth's largest freshwater lakes. Ecosyst. Serv. 2020, 41, 101046. [CrossRef]

38. Austin, J.A.; Colman, S.M. Lake Superior summer water temperatures are increasing more rapidly than regional air temperatures: A positive ice-albedo feedback. Geophys. Res. Lett. 2007, 34. [CrossRef]

39. Reinl, K.L.; Sterner, R.W.; Austin, J.A. Seasonality and physical drivers of deep chlorophyll layers in Lake Superior, with implication for a rapidly warming lake. J. Great Lakes Res. 2020, 46, 1615-1624. [CrossRef]

40. Kraker, D. Duluth Rebuilds Lake Walk to-Hopefully-Withstand Future Storms. MPR News. 2020. Available online: https: //www.mprnews.org/story/2020/12/21/duluth-rebuilds-lakewalk-to-hopefully-withstand-future-storms (accessed on 14 May 2021).

41. Lake Superior Lake Wide Action and Management Plans (LAMP). 2019. Available online: https://binational.net/wp-content/ uploads/2021/03/FINAL-English-Lake-Superior-2019-Annual-Report.pdf (accessed on 15 May 2021).

42. Lake Michigan Lake Wide Action and Management Plans (LAMP). 2018. Available online: https://binational.net/wp-content/ uploads /2019/03/LM_LAMP_AR_2018_final.pdf (accessed on 15 May 2021).

43. Great Lakes Surf Rescue Project. Statistics. Available online: https://glsrp.org/statistics/ (accessed on 13 May 2021).

44. Associated Press. High Water Wreaks Havoc on Great Lakes, Swamping Communities. AP News; 7 February 2020. Available online: https: / /apnews.com/article/lake-michigan-in-state-wire-manistee-mi-state-wire-erosion-cdd234381027aa31138767bd3 d935ef7 (accessed on 15 May 2021).

45. Olson, K.R.; Miller, G.A. St. Lawrence Seaway: Western Great Lakes Basin. J. Water Resour. Prot. 2020, 12, 637-656. Available online: https: / /www.scirp.org/journal/jwarp (accessed on 15 May 2021). [CrossRef]

46. Lake Huron Lake Wide Action and Management Plans (LAMP). 2019. Available online: https://binational.net/wp-content/ uploads/2021/03/English-Lake-Huron-2019-Annual-Report.Mar_.9.2021.pdf (accessed on 15 May 2021).

47. Michigan Dept. of Environment, Great Lakes, and Energy. Great Lakes Map. 2019. Available online: https://www.michigan. gov/egle/0,9429,7-135-3313_3677-15926--,00.html (accessed on 15 May 2021).

48. Lake Erie Lake Wide Action and Management Plans. 2019. Available online: https://binational.net/2021/03/22/lear2019/ (accessed on 15 May 2021). 
49. Lake Ontario Lake Wide Action and Management Plans. 2019. Available online: https://binational.net/wp-content/uploads/20 21/03/FINAL-English-Lake-Ontario-2019-Annual-Report.pdf (accessed on 15 May 2021).

50. New York State Official Website. Governor Cuomo Directs New York State Department of Environmental Conservation to Sue the International Joint Commission for Water Level Mismanagement That Devastated Lake Ontario Shoreline Communities. 19 October 2019. Available online: https:/ / www.governor.ny.gov/news/governor-cuomo-directs-new-york-state-departmentenvironmental-conservation-sue-international (accessed on 15 May 2021).

51. U.S. Census Bureau. TIGER/Line Shapefiles. 2020. Available online: https://www.census.gov/cgi-bin/geo/shapefiles/index. php (accessed on 17 May 2021).

52. USGS GLRI. Great Lakes and Watershed Shapefiles. 2010. Available online: https://www.sciencebase.gov/catalog/item/530f8 a0ee4b0e7e46bd300dd (accessed on 17 May 2021).

53. Hallegatte, S.; Vogt-Schilb, A.; Rozenberg, J.; Bangalore, M.; Beaudet, C. From poverty to disaster and back: A review of the literature. Econ. Dis. Clim. Chang. 2020, 4, 223-247. [CrossRef]

54. Peek, L. Children and disasters: Understanding vulnerability, developing capacities, and promoting resilience-An introduction Child. Youth Environ. 2008, 18, 1-29. Available online: https://www.jstor.org/stable/10.7721/chilyoutenvi.18.1.0001 (accessed on 15 May 2021).

55. McGuire, L.C.; Ford, E.S.; Okoro, C.A. Natural disasters and older US adults with disabilities: Implications for evacuation. Disasters 2007, 31, 49-56. [CrossRef] [PubMed]

56. Wisner, B.; Blaikie, P.; Cannon, T.; Davis, I. The Challenge of Disasters and our Approach. In At Risk: Natural Hazards, People's Vulnerability, and Disasters; Wisner, B., Blaike, P., Cannon, T., Davis, I., Eds.; Routledge Press: London, UK, $1994 ;$ pp. 3-48.

57. Thomas, K.; Hardy, R.D.; Lazarus, H.; Mendez, M.; Orlove, B.; Rivera-Collazo, I.; Roberts, J.T.; Rockman, M.; Warner, B.P.; Winthrop, R. Explaining differential vulnerability to climate change: A social science review. Wiley Interdiscip. Rev. Clim. Chang. 2019, 10, e565. [CrossRef] [PubMed]

58. Pulido, L. Rethinking environmental racism: White privilege and urban development in southern California. Ann. Assoc. Am. Geogr. 2000, 90, 12-40. [CrossRef]

59. Donner, W.R. The political ecology of disaster: An analysis of factors influencing U.S. tornado fatalities and injuries, 1998-2000. Demography 2007, 44, 669-685. [CrossRef] [PubMed]

60. Anselin, L. Local indicator of spatial association-LISA. Geogr. Anal. 1995, 27, 93-115. [CrossRef]

61. Anselin, L. Local spatial autocorrelation (1) LISA and Local Moran. GeoDa Documentation. 2020. Available online: https: //geodacenter.github.io/workbook/6a_local_auto/lab6a.html (accessed on 28 April 2021).

62. Brooks, M.M. The advantages of comparative LISA techniques in spatial inequality research: Evidence from poverty change in the United States. Spat. Demogr. 2019, 7, 167-193. [CrossRef]

63. Koks, E.E.; Jongman, B.; Husby, T.G.; Botzen, W.J.W. Combining hazard, exposure and social vulnerability to provide lessons for flood risk management. Environ. Sci. Policy 2015, 47, 42-52. [CrossRef]

64. Armas, I.; Garvis, A. Social vulnerability assessment using spatial multi-criteria analysis (SEVI model) and the social vulnerability index (SoVi model)—A case study for Bucharest, Romania. Nat. Hazards Earth Syst. Sci. 2013, 13, 1481-1499. [CrossRef]

65. Frigerio, I.; Carnelli, F.; Cabinio, M.; De Amicis, M. Spatiotemporal pattern of social vulnerability in Italy. Int. J. Disaster Risk Sci. 2018, 9, 249-262. [CrossRef]

66. ESRI ArcGIS Desktop. How Cluster and Outlier Analysis (Anselin Local Moran's I) Works. Available online: https:/ / desktop. arcgis.com/en/arcmap/latest/tools/spatial-statistics-toolbox/h-how-cluster-and-outlier-analysis-anselin-local-m.htm (accessed on 29 May 2021).

67. USDA Economic Research Service (ERS). County Typology Codes. 2019. Available online: https://www.ers.usda.gov/dataproducts/county-typology-codes (accessed on 16 May 2021).

68. Lujan, C.C. American Indians and Alaska Natives count: The US Census Bureau's efforts to enumerate the Native population. Am. Indian Q. 2014, 38, 319-341. [CrossRef]

69. Vickery, J.; Hunter, L.M. Native Americans: Where in environmental justice research? Soc. Nat. Resour. 2016, 29, 36-52. [CrossRef]

70. Rufat, S.; Tate, E.; Emrich, C.T.; Antolini, F. How valid are social vulnerability models? Ann. Assoc. Am. Geogr. 2019, 109, 1131-1153. [CrossRef]

71. Krieger, N. A century of census tracts: Health \& the body politic (1906-2006). J. Urban Health 2006, 83, 355-361. [CrossRef] 